\title{
Tyrosine kinase inhibitor-induced CD70 expression mediates drug resistance in leukemia stem cells by activating Wnt-signaling
}

Carsten Riether ${ }^{1}$, Christian M. Schürch ${ }^{1,2 *}$, Christoph Flury $^{1}$, Magdalena Hinterbrandner ${ }^{1}$, Linda

Drück $^{1}$, Anne-Laure Huguenin ${ }^{1}$, Gabriela M. Baerlocher ${ }^{3,4}$, Ramin Radpour ${ }^{1}$, and Adrian F. Ochsenbein ${ }^{1,5} \dagger$

1 Tumor Immunology, Department of Clinical Research, Murtenstrasse 35, University of Bern, 3010 Bern, Switzerland. Telephone: +41-31-632-0956, Fax: +41-31-632-3297

2 Institute of Pathology, Murtenstrasse 31, University of Bern, 3010 Bern, Switzerland. Telephone: +41-31-632-3211, Fax: +41-31-632-3211

3 Experimental Hematology, Department of Clinical Research, Inselspital, University Hospital and University of Bern, 3010 Bern, Switzerland. Telephone: +41-31-632-3306, Fax: +41-31-632-5038

4 Department of Hematology, Inselspital, University Hospital and University of Bern, 3010 Bern, Switzerland. Telephone: +41-31-632-3306, Fax: +41-31-632-5038

5 Department of Medical Oncology, Inselspital, University Hospital and University of Bern, 3010 Bern, Switzerland. Telephone: +41-31-632-4114, Fax: +41-31-632-4119

* C.R. and C.M.S. contributed equally to this work

$\dagger$ Correspondence: Adrian F. Ochsenbein, Institute for Medical Oncology, Inselspital, University Hospital Bern, 3010 Bern, Switzerland.

E-mail: adrian.ochsenbein@ insel.ch, Telephone: +41-31-632-4114, Fax: +41-31-632-4119.

One-sentence summary: TKI-induced CD70 expression mediates drug resistance in LSCs. 


\begin{abstract}
In chronic myelogenous leukemia (CML), oncogenic BCR-ABL1 activates the Wnt pathway, which is fundamental for leukemia stem cell (LSC) maintenance. Tyrosine kinase inhibitor (TKI) treatment reduces Wnt-signaling in LSCs and often leads to molecular remission of CML; however, LSCs persist long-term despite BCR-ABL1 inhibition, ultimately leading to disease relapse. Here, we demonstrate that TKIs induce the expression of the tumor necrosis factor (TNF) family ligand CD70 in LSCs by down-regulating microRNA-29, resulting in reduced CD70 promoter DNA methylation and up-regulation of the transcription factor specificity protein 1. CD70 triggered CD27-signaling and compensatory Wnt pathway activation. Consequently, combining TKIs with CD70 blockade effectively eliminated human CD34 ${ }^{+}$CML stem/progenitor cells in xenografts and LSCs in a murine CML model. Therefore, TKI-induced expression of CD70 and compensatory Wnt-signaling via the CD70/CD27-interaction is a promising targetable resistance mechanism of CML LSCs.
\end{abstract}




\section{Introduction}

Chronic myelogenous leukemia (CML) originates from leukemia stem cells (LSCs) harboring the constitutively active BCR-ABL1 tyrosine kinase (1). Imatinib, a tyrosine kinase inhibitor (TKI) targeting BCR-ABL1, revolutionized CML therapy (2). TKI treatment can lead to long-term remission in CML patients; however, disease-initiating LSCs are resistant to TKIs despite BCR-ABL1 inhibition $(3,4)$. Therefore, definite cure of most patients is still not achievable and CML will ultimately relapse upon drug discontinuation (5). In addition, there is a substantial risk of TKI resistance due to mutations in BCR-ABL1 (5) and disease progression to blast phase (6). Consequently, future therapies must aim at eliminating LSCs by selectively targeting pathways that are crucial for LSC homeostasis. In CML, $\beta$-catenin, a central component of the canonical Wnt pathway, is stabilized by BCR-ABL1 (7) and is essential for LSC self-renewal (8). Therefore, $\beta$-catenin deletion or its pharmacological inhibition eradicates TKI-resistant LSCs (9).

CD27, a costimulatory molecule of the tumor necrosis factor (TNF) receptor superfamily, is constitutively expressed on different immune cells and on hematopoietic and CML stem cells (10-12). We recently reported in a murine model that CD27-signaling in LSCs leads to CML progression (12). CD27-signaling is regulated by the expression of its only ligand CD70 (10). CD70 is not detectable in healthy individuals but is expressed on lymphocytes and subsets of dendritic cells upon immune activation. Therefore, activated CD70 expressing immune cells may contribute to CML progression (13). In addition, several solid tumors and lymphomas have been shown to express CD70, but the relevance and the physiological consequences of CD70 expression on cancer cells are controversial $(10,14)$.

Here, we demonstrate that TKI-mediated BCR-ABL1 inhibition in leukemia cell lines and CD34 ${ }^{+}$ stem/progenitor cells from newly diagnosed CML patients induces expression of CD70 by downregulating microRNA (miR)-29 levels, resulting in reduced $C D 70$ promoter DNA methylation and upregulation of the transcription factor specificity protein 1 (SP1). CD70 expression induced CD27signaling, compensatory Wnt pathway activation and TKI resistance. Co-treatment using TKIs and monoclonal antibodies blocking the CD70/CD27-interaction synergistically reduced leukemia cell proliferation and colony formation in vitro and effectively eradicated human $\mathrm{CD} 34^{+} \mathrm{CML}$ 
stem/progenitor cells in murine xenografts in vivo. Similarly, in a murine CML model, combination therapy eradicated LSCs in a majority of treated animals. Our data reveal a therapeutically targetable mechanism of TKI resistance in CML LSCs. 


\section{Results}

\section{TKI treatment induces CD70 expression in human leukemia cells.}

To analyze the impact of TKI treatment on CD70 expression, we cultured the BCR-ABL1 ${ }^{+}$CML cell line KBM5 in the presence of imatinib. Interestingly, imatinib induced CD70 mRNA and protein expression in a dose-dependent manner (Fig. 1A-C). The CD70 promoter contains binding sites for several transcription factors including SP1 and is methylation sensitive (15). Imatinib treatment resulted in up-regulation of $S P 1$ and down-regulation of DNA methyltransferase 1 (DNMTI) mRNA expression (Fig. 1D-E). Similar results were obtained with the second-generation TKI nilotinib and in different BCR-ABL1 ${ }^{+}$leukemia cell lines such as K562 and SD-1 (fig. S1A-O).

More importantly and in line with these findings, FACS-sorted CD $34^{+}$stem/progenitor cells from newly diagnosed CML patients (see table $\mathrm{S} 1$ for clinical characteristics of the included patients) cultured ex vivo in the presence of imatinib exhibited increased $C D 70$ and SP1 mRNA expression, whereas DNMT1 was down-regulated (Fig. 1F-H).

To elaborate whether the mechanism of TKI-mediated CD70 induction is dependent on BCR-ABL1 inhibition or an off-target effect, we made use of the imatinib-resistant KBM5 cell line harboring the BCR-ABL1 ${ }^{\mathrm{T} 315 \mathrm{I}}$ mutation (referred to as KBM5r). BCR-ABL1 ${ }^{\mathrm{T} 315 \mathrm{I}}$ represents $\sim 20 \%$ of all clinically observed BCR-ABL1 mutations and confers resistance to three TKIs currently used in clinics (imatinib, nilotinib and dasatinib) (16). At the therapeutic concentration of $1 \mu \mathrm{M}$, which is associated with an optimal response in CML patients (17), imatinib treatment did not increase the expression of CD70 protein and $C D 70$ or SP1 mRNAs nor decrease the expression of DNMT1 mRNA in KBM5r cells (fig. S2A-E). Therefore, we cultured KBM5r cells in the presence of the pan-BCR-ABL1 inhibitor ponatinib, which was developed to overcome BCR-ABL1 ${ }^{\mathrm{T} 315 \mathrm{I}}$ mutation-mediated resistance (18) and has proven effective in clinical trials (19). Ponatinib treatment at the therapeutic concentration of $0.1 \mu \mathrm{M}(19)$ induced CD70 protein and mRNA expression, up-regulated SPI and down-regulated DNMT1 mRNA in KBM5r cells (Fig. 1I-M). CD70 protein expression was already up-regulated after 16 hours of treatment (fig. S3A), at a time point where ponatinib did not induce substantial cell death (fig. S3B). This indicates that the observed increase in CD70 expression after 
TKI treatment is due to an up-regulation of the protein rather than a selection of CD70-expressing cells.

To functionally prove that the expression of CD70 after TKI treatment is mediated by SP1, we stably knocked down SP1 in KBM5r cells using short hairpin (sh)SP1 lentiviral particles. SP1 knockdown KBM5r cells did not up-regulate CD70 in the presence of ponatinib compared to scrambled control RNA-transfected cells (Fig. 1N-P).

To elaborate whether the Wnt pathway represents a link between TKI-mediated BCR-ABL1 inhibition and the regulation of $C D 70, S P 1$ and $D N M T 1$, we cultured TKI-treated KBM5r cells in the presence of lithium chloride (20) or the specific Wnt activator R-Spondin 1 (21). Re-activation of Wnt-signaling by lithium or R-Spondin 1 blocked the changes observed after TKI treatment (fig. S4A-F).

$S P 1$ and DNMTs are regulated by $m i R-29(22,23)$. In addition, $m i R-29$ has been shown to modulate Wnt-signaling in a positive feedback loop $(23,24)$. Therefore, we analyzed $m i R-29$ levels in KBM5r cells treated with imatinib, nilotinib and ponatinib. Inhibition of BCR-ABL1 ${ }^{\mathrm{T} 315 \mathrm{I}}$ by ponatinib resulted in down-regulation of all three $m i R-29 s$, whereas imatinib and nilotinib did not affect $m i R-29 s$ (Fig. 2A-C). Individual silencing of the three $m i R-29 s$ using anti-miRs revealed that $S P 1$ expression was increased after $m i R-29 c$ silencing, whereas $D N M T 1$ expression was suppressed after silencing of $m i R$ $29 a$ and $m i R-29 b$ (Fig. 2D-E).

The down-regulation of DNMTI by TKI treatment prompted us to investigate the DNA methylation status of the $C D 70$ promoter. Bisulfite sequencing revealed a strongly methylated $C D 70$ promoter in vehicle-treated KBM5r cells that hardly expressed any detectable CD70 protein or mRNA (Fig. 1I-K, 2F). Consistent with the up-regulation of CD70 mRNA and protein expression, ponatinib treatment significantly reduced $C D 70$ promoter DNA methylation in KBM5r cells, particularly at the SP1 binding site (Fig. 2F-H). Control KBM5r cells cultured in the presence of the DNMT inhibitor azacytidine, a de-methylating agent (25), showed similar reductions in $C D 70$ promoter methylation (Fig. 2F-H).

In summary, these data indicate that TKI-mediated blocking of BCR-ABL1, subsequent Wnt pathway inhibition and suppression of $m i R-29$ induces CD70 expression by reducing its promoter methylation and up-regulating $S P 1$. 


\section{Combined CD70/CD27 and BCR-ABL1 inhibition synergistically reduces Wnt-signaling and}

eradicates leukemia cells in vitro.

SD-1 cells were cultured in the presence of either a blocking $\alpha \mathrm{CD} 27$ monoclonal antibody (mAb) or imatinib alone or both in combination. As previously reported (12), blocking the CD70/CD27interaction reduced SD-1 cell growth by inhibiting cell proliferation (Fig. 3A-B). In contrast, blocking CD27 signaling alone did not affect cell viability (Fig. 3C). In line with its documented ability to induce apoptosis of BCR-ABL1 ${ }^{+}$cells (26), imatinib treatment resulted in SD-1 cell death as analyzed by FACS (Fig. 3C). Imatinib reduced SD-1 cell growth and proliferation to a similar extent as $\alpha \mathrm{CD} 27$ treatment (Fig. 3A-B). Interestingly, compared to single treatments, $\alpha \mathrm{CD} 27 /$ imatinib co-treatment significantly reduced cell growth by inhibiting cell proliferation and enhancing cell death (Fig. 3A-C). Similar results were obtained by treating SD-1 cells with $\alpha \mathrm{CD} 27 \mathrm{mAb}$ and nilotinib (Fig. 3D-F) and by treating KBM5 and KBM5r cells with $\alpha \mathrm{CD} 27 \mathrm{mAb}$ and imatinib or ponatinib, respectively (fig. S5).

To investigate whether the treatment combination with $\alpha \mathrm{CD} 27 \mathrm{mAb}$ and imatinib resulted in synergistic activity, we performed a drug combination study according to the Chou-Talalay method (27). Co-treatment showed synergistic growth inhibition at all concentrations tested (Fig. 3G, fig. S6A-B and table S2).

We could previously demonstrate that the CD70/CD27-interaction on murine CML LSCs activates the Wnt-signaling pathway (12). TKIs such as imatinib reduce aberrant BCR-ABL1-induced Wntsignaling in CML cells (7). To analyze if the synergistic effect on SD-1 cell viability and proliferation of $\alpha \mathrm{CD} 27 /$ imatinib co-treatment was mediated via Wnt pathway inhibition, we performed a lentiviral Wnt-signaling reporter assay and analyzed the expression of selected Wnt target genes. $\alpha \mathrm{CD} 27$ and imatinib single treatments similarly reduced Wnt-signaling and Wnt target gene transcription. Importantly, $\alpha \mathrm{CD} 27 / \mathrm{imatinib}$ co-treatment inhibited Wnt pathway activation significantly stronger than each of the single compounds alone (Fig. 3H-I). In contrast, Notch, Hedgehog and MAP kinase pathways were not or only minimally affected by the $\alpha \mathrm{CD} 27 /$ imatinib co-treatment (fig. S6C). 


\section{CD70/CD27 and BCR-ABL1 co-inhibition promotes cell death of human CML stem/progenitor}

cells.

Next, we investigated the functional role of increased CD27-signaling in response to imatinib-induced CD70 up-regulation in MACS-purified human CD34 ${ }^{+}$CML stem/progenitor cells. CD27 and CD70 expression were determined by FACS (Figs. 4A-D). To analyze the level of the CD70/CD27interaction (CD27-signaling) in the different patient samples, we measured soluble CD27 (sCD27) in the cell supernatants. Ligation of CD27 by CD70 results in shedding of CD27 from the cellular membrane and release of sCD27 (10). Treatment of CD34 ${ }^{+}$CML stem/progenitor cells with a blocking human $\alpha \mathrm{CD} 70 \mathrm{mAb}$ (clone 41D12-D) resulted in up-regulation of membrane-bound CD27 (Figs. 4A,C) and lower levels of sCD27 (Fig. 4E). The expression of CD70 was not altered after $\alpha \mathrm{CD} 70$ mAb treatment (Fig. 4B,D). sCD27 levels were very comparable in all supernatants of untreated patient samples and were similarly reduced after $\alpha \mathrm{CD} 70$ treatment. This indicates that the level of CD27 ligation was quite similar between patient samples.

Single treatments with either $\alpha \mathrm{CD} 70 \mathrm{mAb}$ or imatinib inhibited growth and proliferation of FACSsorted CD34 ${ }^{+}$CML stem/progenitor cells (Fig. 4F-G). The human $\alpha \mathrm{CD} 70 \mathrm{mAb}$ (clone 41D12-D) was specifically designed to block the CD70/CD27-interaction without inducing effector functions such as antibody-dependent cell-mediated or complement-mediated cytotoxicity and antibody-dependent cellmediated phagocytosis (28). In line with our results using the blocking $\alpha \mathrm{CD} 27 \mathrm{mAb}$ and SD-1 cells (Fig. 3A-F), single $\alpha \mathrm{CD} 70$ treatment inhibited cell proliferation without affecting cell viability, whereas single imatinib treatment reduced cell proliferation and induced cell death (Fig. 4G-I). Importantly, $\alpha \mathrm{CD} 70 /$ imatinib co-treatment potently reduced CD34 ${ }^{+} \mathrm{CML}$ stem/progenitor cells in liquid cultures by inhibiting cell proliferation and increasing cell death (Fig. 4G-I). In addition, colony formation in semi-solid cultures was significantly impaired by co-treatment compared to single treatments (Fig. 4J). Control CD34 ${ }^{+}$hematopoietic stem/progenitor cells from patients who underwent BM aspirate for other reasons than leukemia («healthy donors») were only marginally affected by $\alpha \mathrm{CD} 70$ or imatinib treatment in vitro (fig. S7A-E). 
$\alpha C D 70 /$ imatinib co-treatment eradicates human $\mathrm{CD34}^{+} \mathrm{CML}$ stem/progenitor cells in murine xenografts.

To validate our findings in vivo, we employed a previously described murine CML xenograft model (29, 30) using NOD/LtSz-scid IL2R $\gamma^{\text {null }}$ (NSG) mice (31). 2x10 ${ }^{6}$ MACS-sorted CD34 ${ }^{+} \mathrm{CML}$ stem/progenitor cells from the blood of patients 3,4 and 5 carrying different BCR-ABL1 translocations (table S1) were injected intravenously into sublethally irradiated (2.75 Gy) NSG mice. After seven days of engraftment, NSG mice were randomized to receive vehicle, imatinib or $\alpha \mathrm{CD} 70$ treatment alone or $\alpha \mathrm{CD} 70 /$ imatinib co-treatment. Imatinib plasma levels in xenografted NSG mice were in the published therapeutic range of $1 \mu \mathrm{M}$ (fig. S8) (17). After two weeks of treatment, animals were sacrificed and the $\mathrm{BM}$ was analyzed for human $\mathrm{CD} 45^{+} \mathrm{CD} 33^{+} \mathrm{CML}$ myeloid cells and $\mathrm{CD}^{+} 5^{+} \mathrm{CD} 34^{+} \mathrm{CML}$ stem/progenitor cells (Fig. 5A-E). At that time point, vehicle-treated NSG mice had a frequency of $11.8 \pm 1.1 \%$ of human $\mathrm{CD} 45^{+} \mathrm{CD} 33^{+} \mathrm{CML}$ myeloid cells in the BM (Fig. 5B). Single $\alpha \mathrm{CD} 70$ or imatinib treatment significantly reduced cell frequencies and absolute numbers of $\mathrm{CD}^{+} 5^{+} \mathrm{CD} 33^{+}$leukemia cells and leukemia-initiating CD34 ${ }^{+} \mathrm{CML}$ stem/progenitor cells (Fig. 5C-E). $\alpha \mathrm{CD} 70 /$ imatinib co-treatment further reduced $\mathrm{CD} 45^{+} \mathrm{CD} 33^{+} \mathrm{CML}$ myeloid cells (Fig. 5C-D) and, importantly, eradicated the leukemia-initiating CD34 ${ }^{+} \mathrm{CML}$ stem/progenitor cells in the BM of 9 out of 12 NSG mice (Fig. 5E).

CD34 ${ }^{+}$CML stem/progenitor cells isolated ex vivo from xenografted vehicle-treated NSG mice expressed CD70 (Fig. 5F and fig. S9A) but only low levels of CD27 (fig. S9B-C). CD70 and CD27 were not expressed on more differentiated CD34 CML cells (Fig. 5F and fig. S9C). Imatinib treatment of xenografted NSG mice specifically increased CD70 expression on $\mathrm{CD} 34^{+} \mathrm{CML}$ stem/progenitor cells but not on CD34 CML cells (Fig. 5F,G). In contrast, the expression of CD27 remained unchanged after TKI treatment (fig. S9C). In addition, imatinib treatment induced an up-regulation of $S P 1$ and decreased the expression of DNMT1 and miR-29a,b and $c$ in CD34 $4^{+}$CML stem/progenitor cells in vivo (Fig. 5H-L).

To analyze if CD70 expression correlates with Wnt pathway activation in CML patients harboring the $\mathrm{b} 3 \mathrm{a} 2$ or the $\mathrm{b} 2 \mathrm{a} 2 \mathrm{BCR}-\mathrm{ABL} 1$ translocation, we made use of expression data derived from a public repository for microarray data (accession number E-MEXP-480; http://www.ebi.ac.uk/arrayexpress). 
Independent of the BCR-ABL1 translocation, CD70 expression positively correlated with the expression of Wnt target genes (Fig. 5M-N).

\section{TKI treatment induces CD70 expression in murine CML LSCs.}

Since human CD34 ${ }^{+}$CML stem/progenitor cells do not engraft long-term in NSG mice (29), we also tested our co-treatment strategy in a well-established syngeneic CML model (12). BM from donor BL/6 mice was transduced with BCR-ABL1-GFP and injected into sublethally irradiated (4.5 Gy) recipients. First, we intended to study the effects of imatinib single treatment on the expression of CD70 protein and $C d 70, S p 1$ and Dnmt1 mRNA in murine LSCs in vivo. In analogy to murine hematopoietic stem cells (HSCs) (32), murine LSCs reside in a BM cell population characterized by the lack of lineage markers and by the expression of stem cell antigen-1 (Sca-1) and c-kit (lin-Sca- $1^{+} \mathrm{c}-$ kit $^{\text {hi }}$ cells, LSKs, fig. S10) (33). CML-bearing mice were either treated with vehicle or imatinib and CD70 expression in BCR-ABL1-GFP ${ }^{+}$LSKs was analyzed. Consistent with our data obtained for KBM5 cells and human CD34 ${ }^{+}$CML stem/progenitor cells in vitro, BCR-ABL1-GFP ${ }^{+}$LSKs from imatinib-treated CML mice expressed significantly higher levels of CD70 protein and mRNA as compared to BCR-ABL1-GFP ${ }^{+}$LSKs from vehicle-treated mice (Fig. 6A-C and fig. S10). Moreover, imatinib treatment increased Spl and decreased Dnmt1 mRNA in BCR-ABL1-GFP ${ }^{+}$LSKs (Fig. 6DE). Importantly, CD70 up-regulation upon imatinib treatment was specific for BCR-ABL1-GFP ${ }^{+}$ LSKs, as imatinib did not alter CD70 expression on BCR-ABL1-GFP ${ }^{+}$c-kit ${ }^{\text {hi }}$ Sca- $1^{-}$leukemia progenitors (fig. S10 and fig. S11A). Furthermore, CD70, Sp1 and Dnmt1 expression did not change in endogenous non-malignant GFP' LSKs upon imatinib treatment (Fig. 6A and fig. S11B-E).

As previously demonstrated, the CD70/CD27-interaction on murine CML LSCs activates the Wntsignaling pathway via TNF receptor associated factor 2 (TRAF2) and the TRAF2- and NCKinteracting protein kinase (TNIK) (12). Even though imatinib treatment did not affect CD27 expression on BCR-ABL1-GFP ${ }^{+}$LSKs, Traf2 and Tnik were up-regulated on mRNA level while Wnt target genes such as Runxl and Myc were down-regulated (fig. S11F-J). These results are in line with and further support the hypothesis that TKIs specifically alter the expression of CD70, SP1 and 
DNMT1 via BCR-ABL1 inhibition and increase the expression of CD27 downstream signaling molecules such as TRAF2 and TNIK.

\section{$\alpha C D 70 /$ imatinib combination therapy eliminates murine CML LSCs in vivo.}

In a second step, we intended to analyze the effect of combining TKI treatment with CD70/CD27 inhibition on the survival of CML mice. 15 days after transplantation, mice harboring comparable leukemia loads $\left(49 \pm 5\right.$ BCR-ABL1-GFP ${ }^{+} \mathrm{Gr}^{+} 1^{+}$granulocytes/ $\mu$ l blood $)$ were randomized to monotherapy with either vehicle, imatinib or a blocking $\alpha \mathrm{CD} 70 \mathrm{mAb}$ (clone FR70) $(34,35)$ or $\alpha \mathrm{CD} 70 /$ imatinib combination therapy and disease development and survival were monitored. Monotherapy significantly delayed leukemia development and prolonged survival compared to the vehicle group; nevertheless, all animals eventually succumbed to CML. $\alpha \mathrm{CD} 70 /$ imatinib combination therapy significantly improved survival of CML mice compared to monotherapy, and $60 \%$ of the animals receiving the combination therapy were alive 90 days after transplantation (Fig. 6F). This suggested that CML stem/progenitor cells were completely eradicated or at least effectively controlled long-term in these mice.

In order to investigate this issue, surviving mice were sacrificed and spleen weights and BM BCRABL1-GFP ${ }^{+} l i n{ }^{-}$cell frequencies were determined. In this experiment, 1 out of 8 surviving mice displayed a splenomegaly; this and two other mice harbored detectable levels of BCR-ABL1-GFP ${ }^{+}$lin $^{-}$ cells in the BM, indicating the presence of CML (fig. S12A-B). Secondary transplantation of $1 \times 10^{7}$ whole BM (WBM) cells from these 3 mice induced fatal CML in lethally irradiated (2x6.5 Gy) BL/6 recipients (Fig. 6G). In contrast, secondary recipients receiving WBM cells from the other 5 donors survived up to 90 days without signs of leukemia (Fig. $6 \mathrm{G}$ ). This indicates that $\alpha \mathrm{CD} 70 /$ imatinib cotreatment targeted and eliminated the disease-initiating LSCs in 5 out of 8 of the primary CML animals.

The BCR-ABL1-GFP ${ }^{+}$LSK cell population that contains the LSCs is heterogeneous and hierarchically organized and can be further sub-divided into long-term (LT-)LSCs, short-term (ST-)LSCs and leukemia multipotent progenitors (MPPs) using the markers CD150, CD135 and CD48 (30, 36). To 
analyze the impact of combination therapy on these LSC sub-populations in more detail, especially on the disease-initiating LT-LSCs (36), CML mice harboring comparable leukemia loads $(163 \pm 20$ BCR/ABL-GFP ${ }^{+} \mathrm{Gr}-1^{+}$granulocytes/ $\mu$ l blood) 15 days after transplantation received either imatinib alone or $\alpha \mathrm{CD} 70 /$ imatinib combination therapy. 10 days later, mice were sacrificed and $\mathrm{BM}$ and spleen were analyzed. Compared to imatinib monotherapy, $\alpha \mathrm{CD} 70 /$ imatinib combination therapy resulted in significantly lower spleen weights and a lower leukemia load as indicated by lower numbers of BCRABL1-GFP ${ }^{+} \mathrm{Gr}-1^{+}$granulocytes in the blood as well as lower numbers of BCR-ABL1-GFP ${ }^{+}$lin leukemia cells and $\mathrm{BCR}-\mathrm{ABL} 1-\mathrm{GFP}^{+} \operatorname{lin}^{-} \mathrm{c}^{-\mathrm{kit}^{\mathrm{hi}}}$ leukemia progenitors in the BM (fig. S12C-F). Importantly, $\alpha \mathrm{CD} 70 /$ imatinib combination therapy more efficiently eliminated the BCR-ABL1-GFP ${ }^{+}$ LSK cell population including the disease-initiating LT-LSCs than imatinib monotherapy (Fig. 6H-J and fig. S12G-H).

In addition, lin ${ }^{-} \mathrm{BM}$ cells from $\alpha \mathrm{CD} 70 /$ imatinib co-treated $\mathrm{CML}$ animals formed significantly fewer BCR-ABL1-GFP ${ }^{+}$colonies than lin ${ }^{-}$cells from imatinib-treated mice (Fig. $6 \mathrm{~K}$ ). To further prove that the findings from FACS analysis and colony assays in vitro actually account for reduced numbers of LSCs in vivo, $3 \times 10^{6} \mathrm{WBM}$ cells from imatinib- or $\alpha \mathrm{CD} 70 /$ imatinib-treated CML mice were transplanted into sublethally irradiated (4.5 Gy) secondary recipients. Recipients that received WBM cells from imatinib-treated leukemia mice all succumbed to CML. In contrast, 5 out of 6 mice receiving WBM cells from mice that had been treated with the $\alpha \mathrm{CD} 70 \mathrm{mAb} / \mathrm{imatinib}$ combination therapy completely eliminated the disease and were alive 90 days after secondary transplantation without signs of leukemia (Fig. 6L).

In summary, these data provide evidence that combination therapy using TKI and CD70/CD27 inhibition selectively targets CML LSCs, particularly the disease-initiating LT-LSCs in vivo. 


\section{Discussion}

In myeloid leukemias, intrinsic and extrinsic factors mediate drug resistance in LSCs and constitute important barriers to current treatment strategies (37). Intrinsic drug resistance mechanisms, such as quiescence, the expression of ATP-binding cassette $(\mathrm{ABC})$ transporters and pre-existing or acquired BCR-ABL1 mutations protect LSCs from both DNA-damaging agents and TKIs $(1,37,38)$. Several approaches were proposed to overcome these intrinsic resistance mechanisms, including two-step therapy regimens using cell cycle-activating drugs followed by TKIs or chemotherapy (39) and the specific targeting of ABC transporters (40). Furthermore, next-generation TKIs with improved efficacy against mutated BCR-ABL1 were successfully developed and introduced into clinical practice (18). However, recent studies demonstrated that LSC survival and persistence are independent of BCR-ABL1 $(3,4)$ and therefore, even next-generation TKIs will most likely be ineffective against LSCs when used as monotherapy.

In addition, accumulating evidence indicates that extrinsic factors from the BM microenvironment play an essential role in regulating LSC survival, self-renewal and drug resistance (37, 41). In analogy to HSCs, LSCs reside in and depend on BM niches consisting of cell types such as osteoblasts, mesenchymal stromal cells (MSCs) and endothelial cells $(13,42)$. These niche cells provide soluble and cell contact-dependent signals, including cytokines, chemokines, Wnt, Notch and Hedgehog ligands as well as integrins and cadherins that maintain LSC homeostasis (42). MSCs have been shown to support LSC adhesion and promote TKI resistance via $\mathrm{N}$-cadherin and $\beta$-catenin (43). Moreover, in leukemia, BM-infiltrating immune cells may contribute to the LSC niche and especially activated T cells interact with and paradoxically support LSCs $(12,13,44)$.

The canonical Wnt pathway is essential for the maintenance of stem cell characteristics of LSCs such as quiescence, self-renewal and the regulation of cell fate $(8,9)$. In CML, BCR-ABL1 induces stabilization of $\beta$-catenin and thereby contributes to Wnt pathway activation (7). However, although BCR-ABL1-specific TKIs inhibit $\beta$-catenin stability and thereby Wnt-signaling, it is well documented that LSCs are resistant to TKI treatment $(3,4)$. Here, we document that in response to TKI treatment and Wnt pathway inhibition, CML stem cells induce the expression of CD70. The CD70/CD27- 
interaction leads to compensatory Wnt pathway activation and thereby confers resistance of LSCs to TKI treatment. Under physiological conditions, CD70 is only expressed by activated lymphocytes and subsets of dendritic cells (10). In CML, activated CD70-expressing immune cells induced Wntsignaling in CD27-expressing LSCs, leading to disease progression (12). However, CD70 is also expressed after malignant transformation and has been detected on lymphomas and several solid tumors (10). CD70 was expressed at very low levels on malignant CML cells and was up-regulated on LSCs upon treatment with TKIs. Interestingly, it has been reported previously that CD70 expression is similarly induced upon irradiation on human glioblastoma and prostate carcinoma cells $(45,46)$. In response to TKI treatment, LSCs express both CD27 and CD70. Therefore, CD27-signaling could be induced in a cell-autonomous and/or paracrine manner. However, in vivo, LSCs are supposed to be a rare cell population present as single cells in the $\mathrm{BM}$ in a specialized niche microenvironment in analogy to HSCs $(13,42)$. Therefore, it is most likely that CD27-signaling triggered by CD70 is induced in a cell-autonomous manner.

We found that BCR-ABL1 inhibition reduced $m i R-29$ expression. Our data with lithium- or R-Spondin 1-induced activation of the Wnt pathway are in agreement with earlier results in human MSCs indicating that Wnt-signaling directly increases $m i R$-29 expression (47). Down-regulation of $m i R-29 c$ increased the expression of its direct target SP1, a transcription factor with binding site in the $C D 70$ promoter (22) and SP1 knockdown prevented CD70 up-regulation in response to TKI. In addition, $m i R-29 a, b$ down-regulation was associated with a reduced expression of DNMT1 leading to CD70 promoter de-methylation. These combined effects resulted in CD70 up-regulation on LSCs, increased CD70/CD27-signaling and subsequently restored Wnt pathway activity (Fig. 7). We hypothesize that during BCR-ABL1 inhibition, constant CD70 expression on LSCs is needed to sustain compensatory Wnt-signaling. Therefore, blocking CD70/CD27-signaling in combination with TKIs synergistically inhibited the Wnt pathway and eradicated leukemia cells in vitro. More importantly, combination therapy effectively eliminated the disease-initiating LSCs in murine xenografts and in the murine CML model in vivo. However, because combination therapy resulted in the elimination of LSCs, we could not investigate whether CD70-triggered Wnt-signaling regulates CD70 expression. 
In summary, our study indicates that blocking CD70/CD27-signaling in combination with TKI treatment overcomes compensatory Wnt activation and represents an attractive therapeutic strategy to specifically target CML LSCs. 


\section{Materials and Methods}

\section{Study design}

In vitro experiments. In hypothesis-driven experimental designs, we addressed the molecular mechanisms of TKI-induced CD70 expression in CML cell lines and blood or BM samples from newly diagnosed CML patients treated in vitro with TKIs. Combination therapy using TKIs and blocking mAb was applied and its effect on Wnt pathway activation, CML cell growth and LSC activity was assessed.

Mice. In hypothesis-driven experimental designs, we addressed the molecular mechanisms of TKIinduced CD70 expression in LSCs in a murine model of CML and patient-derived xenografts using $\mathrm{CD}^{+} 4^{+}$stem/progenitor cells from newly diagnosed CML patients. Combination therapy using TKIs and blocking mAb was applied and its effect on Wnt pathway activation, leukemia development, survival, LSC proliferation and LSC activity was assessed.

\section{Antibodies and reagents for treatment}

Murine $\alpha \mathrm{CD} 70$ (clone FR70) was from BioXCell and control IgG from rat serum (rat-IgG) was from Sigma-Aldrich. Human $\alpha \mathrm{CD} 27$ (clone 1A4) and the corresponding isotype control (clone 15H6) were from Beckman Coulter. Human $\alpha \mathrm{CD} 70$ (clone 41D12-D) and a corresponding control mAb specific for the F protein of respiratory syncytial virus (Pavilizumab, Synagis ${ }^{\circledR}$ ) were kindly provided by arGEN-X (Breda, The Netherlands). Imatinib and nilotinib were kindly provided by Novartis. Ponatinib was from Selleck Chemicals. Lithium chloride was from Sigma-Aldrich. Recombinant human R-Spondin 1 was from R\&D Systems.

\section{Patient samples}

Peripheral blood samples and one BM aspirate from untreated, newly diagnosed CML patients at the Department of Hematology, Inselspital, University Hospital and University of Bern, Switzerland, were obtained after written informed consent. Patient characteristics are listed in table S1. Analysis of blood and BM samples was approved by the local ethical committee of the Canton of Bern, Switzerland. 


\section{In vitro experiments}

Cell lines. The human leukemia cell lines SD-1, K562, KBM5 and KBM5r have been described before (48-50).

Liquid culture of primary human CD34 ${ }^{+}$CML stem/progenitor cells. CD34 ${ }^{+}$stem/progenitor cells of human CML patients were cultured and analyzed as previously described (44).

Colony assays. Colony assays with FACS-purified CD $34^{+}$stem/progenitor cells from CML patients or MACS-purified BM lin cells from CML mice were performed as previously described (44).

DNA methylation analysis of the $C D 70$ promoter. Bisulfite conversion of isolated DNA samples from KBM5r cells were assessed using the Epitect $^{\circledR}$ Bisulfite Kit (Qiagen) according to the manufacturer's protocol. The promoter region covering binding sites for important transcription factors was selectively amplified using the following primers: forward primer (-227 -205): 5'GTTTTAGAAGAATGAGGTGGAG-3'; $\quad$ reverse primer $(+14 \sim+35)$ : 5'TCAACCTATCAAAAAACCAAC-3'. For the amplification of bisulfite-treated genomic DNA (gDNA), the following PCR conditions were used: $1 \mathrm{x} 95^{\circ} \mathrm{C}$ for $10 \mathrm{~min}$; $40 \mathrm{x} 95^{\circ} \mathrm{C}$ for $30 \mathrm{~s}, 58^{\circ} \mathrm{C}$ for $40 \mathrm{~s}, 72^{\circ} \mathrm{C}$ for $1 \mathrm{~min} ; 1 \mathrm{x} 72^{\circ} \mathrm{C}$ for $5 \mathrm{~min}$. The PCR cocktail consisted of $3 \mu \mathrm{l}$ of DNA (of at least $10 \mathrm{ng} / \mu \mathrm{l}$ DNA for a final concentration of $3 \mathrm{ng} / \mu \mathrm{l}$ per reaction) in a $25 \mu$ l total volume using $0.5 \mathrm{pmol}$ of each primer, $200 \mu \mathrm{M}$ dNTPs, $0.2 \mathrm{U}$ Hot Start Taq DNA polymerase, $1.5 \mathrm{mM} \mathrm{MgCl}{ }_{2}$ and the buffer supplied with the enzyme. The amplified promoter region was gel-purified and subjected for fluorescent Sanger sequencing (51). The relative quantification of the methylated allele (C) versus unmethylated allele (T) was assessed by the QSVAnalyser software (52). The ratio for methylated cytosine was used for the two-way hierarchical clustering analysis. The variable $\mathrm{CpG}$ fragments at the $C D 70$ promoter were clustered based on pair-wise Euclidean distances and linkage algorithm for all of the 21 samples (7 independent replicates per condition) as previously described (51). The procedure was performed using the double dendrogram function of the Gene Expression Statistical software (NCSS, Kaysville, Utah, USA). 


\section{Animal experiments}

Animal experiments were approved by the local experimental animal committee of the Canton of Bern and performed according to Swiss laws for animal protection.

Mice. C57BL/6J (BL/6) mice were from RCC Ltd. (Füllinsdorf, Switzerland). NOD/LtSz-scid IL2R $\gamma^{\text {null }}$ (NSG) mice have been described before (31).

Murine xenografts. $2 \times 10^{6}$ MACS-purified CD34 ${ }^{+}$stem/progenitor cells from the blood of a newly diagnosed CML patient (patient 4) were injected i.v. into previously sublethally irradiated (2.75Gy) NSG mice. Starting one week after transplantation, imatinib $(50 \mathrm{mg} / \mathrm{kg})$ was administered once daily by oral gavage. The $\alpha \mathrm{CD} 70 \mathrm{mAb}$ (clone 41D12-D) (10mg/kg) was administered i.p. every $3^{\text {rd }}$ day. Sterile $\mathrm{H}_{2} \mathrm{O}$ and Synagis ${ }^{\circledR}$ were used as control treatments. After 2 weeks of treatment, mice were euthanized and BM from femurs and tibias was analyzed by FACS for human cell engraftment using ahuman CD45, CD34, CD33, CD3 and CD19 antibodies.

Murine CML model. CML was induced and monitored as described (12, 44). Briefly, donor mice were treated with $150 \mathrm{mg} / \mathrm{kg}$ of 5-fluorouracil intraperitoneally (i.p.). Six days later, BM was harvested and transduced twice with BCR-ABL1-GFP retrovirus by spin infection. $1 \times 10^{5}$ cells were injected intravenously (i.v.) into the tail vein of sublethally irradiated (4.5 Gy) syngeneic recipients.

Treatment of CML mice was started 15 days after transplantation. Imatinib $(50 \mathrm{mg} / \mathrm{kg}$ ) was

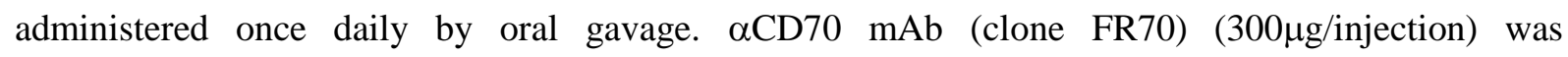
administered i.p every $3^{\text {rd }}$ day. Sterile $\mathrm{H}_{2} \mathrm{O}$ and rat-IgG were used as control treatments.

To detect residual LSC activity in surviving CML mice (90 days after primary transplantation), $1 \times 10^{7}$ whole BM (WBM) cells were injected i.v. into lethally irradiated (twice 6.5 Gy with 4 hours interval) recipient mice.

To compare LSC activity in mice receiving imatinib monotherapy and vs. $\alpha \mathrm{CD} 70 /$ imatinib combination therapy, primary CML mice were treated for 10 days, were sacrificed and $3 \times 10^{6} \mathrm{WBM}$ cells were injected i.v. into sublethally irradiated $(4.5 \mathrm{~Gy})$ recipient mice.

Leukemia stem cell analysis. Leukemia stem cell numbers in CML mice were analyzed by FACS as previously described $(30,44)$. Briefly, LSC sub-populations in lin ${ }^{-B C R}-\mathrm{ABL} 1-\mathrm{GFP}^{+} \mathrm{BM}$ cells were defined as follows: LT-LSCs (Sca- $1^{+}$c-kit $\left.{ }^{\mathrm{hi}} \mathrm{CD} 135^{-} \mathrm{CD} 48^{-} \mathrm{CD} 150^{+}\right)$; ST-LSCs (Sca- $1^{+}$c-kit ${ }^{\mathrm{hi}} \mathrm{CD} 135^{-}$ 
$\mathrm{CD} 48^{-} \mathrm{CD} 150^{-}$); leukemia multipotent progenitor 1s (MPP1s: Sca- $1^{+} \mathrm{c}-\mathrm{kit}^{\mathrm{hi}} \mathrm{CD} 135^{-} \mathrm{CD} 48^{+} \mathrm{CD} 150^{+}$) and MPP2s (Sca- $1^{+}$c-kit $\left.{ }^{\text {hi }} \mathrm{CD} 135^{-} \mathrm{CD} 48^{+} \mathrm{CD} 150^{-}\right)$.

\section{Statistical analysis}

Statistical analysis was performed using GraphPad Prism ${ }^{\circledR}$ 5.0 (GraphPad Software). The details of the test carried out are indicated in the figure legends. Data are represented as mean \pm s.e.m and distributed approximately normally. Data were analyzed using one-way analysis of variance (ANOVA) and Tukey's or Dunnett's multiple comparison test, two-way ANOVA and Bonferroni post-test or student's t-test (two-tailed). Significance of differences in Kaplan-Meier survival curves was determined using the log-rank test (two-tailed). In all cases, $P<0.05$ was considered significant. 


\section{Supplementary Materials}

Materials and Methods

Fig. S1. TKI treatment induces CD70 expression on human BCR-ABL1 ${ }^{+}$leukemia cell lines.

Fig. S2. TKI treatment mediates CD70 induction via BCR-ABL1 inhibition.

Fig. S3. CD70 up-regulation is induced early after TKI treatment in KBM5r cells.

Fig. S4. Activation of Wnt-signaling by lithium chloride or R-Spondin 1 restores TKI-mediated changes in gene expression.

Fig. S5. BCR-ABL1 and CD70/CD27 co-inhibition reduces the expansion of KBM5 and KBM5r CML cells in vitro.

Fig. S6. BCR-ABL1 and CD70/CD27 co-inhibition synergistically reduces cell growth and Wnt pathway activation in SD-1 cells.

Fig. S7. Combination treatment only marginally affects «healthy donor» BM stem/progenitor cells.

Fig. S8. Analysis of imatinib plasma levels in xenografted CML mice.

Fig. S9. Analysis of CD70 and CD27 expression on primary human CML cells.

Fig. S10: Gating scheme to determine CD70 expression on murine LSCs and endogenous nonmalignant GFP ${ }^{-}$LSKs after imatinib treatment.

Fig. S11. TKI treatment induces CD70 expression on murine LSCs but not on leukemia progenitors or endogenous non-malignant GFP' LSKs.

Fig. S12. Combination therapy eradicates LSCs and promotes long-term survival of CML mice.

Table S1. Patient characteristics.

Table S2. Synergistic growth inhibition of SD-1 cells by targeting BCR-ABL1 and CD27-signaling. Table S3. List of primers. 


\section{References and Notes}

1. E. Kavalerchik, D. Goff, C. H. Jamieson, Chronic myeloid leukemia stem cells. J Clin Oncol 26, 2911-2915 (2008).

2. B. J. Druker, M. Talpaz, D. J. Resta, B. Peng, E. Buchdunger, J. M. Ford, N. B. Lydon, H. Kantarjian, R. Capdeville, S. Ohno-Jones, C. L. Sawyers, Efficacy and safety of a specific inhibitor of the BCR-ABL tyrosine kinase in chronic myeloid leukemia. $N$ Engl J Med 344, 1031-1037 (2001).

3. A. S. Corbin, A. Agarwal, M. Loriaux, J. Cortes, M. W. Deininger, B. J. Druker, Human chronic myeloid leukemia stem cells are insensitive to imatinib despite inhibition of BCRABL activity. J Clin Invest 121, 396-409 (2011).

4. A. Hamilton, G. V. Helgason, M. Schemionek, B. Zhang, S. Myssina, E. K. Allan, F. E. Nicolini, C. Muller-Tidow, R. Bhatia, V. G. Brunton, S. Koschmieder, T. L. Holyoake, Chronic myeloid leukemia stem cells are not dependent on Bcr-Abl kinase activity for their survival. Blood 119, 1501-1510 (2012).

5. M. Savona, M. Talpaz, Getting to the stem of chronic myeloid leukaemia. Nat Rev Cancer $\mathbf{8}$, 341-350 (2008).

6. S. Faderl, M. Talpaz, Z. Estrov, S. O'Brien, R. Kurzrock, H. M. Kantarjian, The biology of chronic myeloid leukemia. N Engl J Med 341, 164-172 (1999).

7. A. M. Coluccia, A. Vacca, M. Dunach, L. Mologni, S. Redaelli, V. H. Bustos, D. Benati, L. A. Pinna, C. Gambacorti-Passerini, Bcr-Abl stabilizes beta-catenin in chronic myeloid leukemia through its tyrosine phosphorylation. Embo J 26, 1456-1466 (2007).

8. C. Zhao, J. Blum, A. Chen, H. Y. Kwon, S. H. Jung, J. M. Cook, A. Lagoo, T. Reya, Loss of beta-catenin impairs the renewal of normal and CML stem cells in vivo. Cancer Cell 12, 528541 (2007).

9. F. H. Heidel, L. Bullinger, Z. Feng, Z. Wang, T. A. Neff, L. Stein, D. Kalaitzidis, S. W. Lane, S. A. Armstrong, Genetic and pharmacologic inhibition of beta-catenin targets imatinibresistant leukemia stem cells in CML. Cell stem cell 10, 412-424 (2012). 
10. M. A. Nolte, R. W. van Olffen, K. P. van Gisbergen, R. A. van Lier, Timing and tuning of CD27-CD70 interactions: the impact of signal strength in setting the balance between adaptive responses and immunopathology. Immunol Rev 229, 216-231 (2009).

11. A. Wiesmann, R. L. Phillips, M. Mojica, L. J. Pierce, A. E. Searles, G. J. Spangrude, I. Lemischka, Expression of CD27 on murine hematopoietic stem and progenitor cells. Immunity 12, 193-199 (2000).

12. C. Schürch, C. Riether, M. S. Matter, A. Tzankov, A. F. Ochsenbein, CD27 signaling on chronic myelogenous leukemia stem cells activates Wnt target genes and promotes disease progression. The Journal of clinical investigation 122, 624-638 (2012).

13. C. Riether, C. M. Schürch, A. F. Ochsenbein, Regulation of hematopoietic and leukemic stem cells by the immune system. Cell death and differentiation 22, 187-198 (2015).

14. I. S. Grewal, CD70 as a therapeutic target in human malignancies. Expert opinion on therapeutic targets 12, 341-351 (2008).

15. Q. Lu, A. Wu, B. C. Richardson, Demethylation of the same promoter sequence increases CD70 expression in lupus $\mathrm{T}$ cells and $\mathrm{T}$ cells treated with lupus-inducing drugs. J Immunol 174, 6212-6219 (2005).

16. M. W. Deininger, Optimizing therapy of chronic myeloid leukemia. Exp Hematol 35, 144-154 (2007).

17. M. Koren-Michowitz, Y. Volchek, E. Naparstek, I. Gavish, I. Levi, J. M. Rowe, A. Shimoni, A. Nagler, Imatinib plasma trough levels in chronic myeloid leukaemia: results of a multicentre study CSTI571AIL11TGLIVEC. Hematol Oncol 30, 200-205 (2012).

18. T. O'Hare, W. C. Shakespeare, X. Zhu, C. A. Eide, V. M. Rivera, F. Wang, L. T. Adrian, T. Zhou, W. S. Huang, Q. Xu, C. A. Metcalf, 3rd, J. W. Tyner, M. M. Loriaux, A. S. Corbin, S. Wardwell, Y. Ning, J. A. Keats, Y. Wang, R. Sundaramoorthi, M. Thomas, D. Zhou, J. Snodgrass, L. Commodore, T. K. Sawyer, D. C. Dalgarno, M. W. Deininger, B. J. Druker, T. Clackson, AP24534, a pan-BCR-ABL inhibitor for chronic myeloid leukemia, potently inhibits the T315I mutant and overcomes mutation-based resistance. Cancer Cell 16, 401-412 (2009). 
19. J. E. Cortes, H. Kantarjian, N. P. Shah, D. Bixby, M. J. Mauro, I. Flinn, T. O'Hare, S. Hu, N. I. Narasimhan, V. M. Rivera, T. Clackson, C. D. Turner, F. G. Haluska, B. J. Druker, M. W. Deininger, M. Talpaz, Ponatinib in refractory Philadelphia chromosome-positive leukemias. $N$ Engl J Med 367, 2075-2088 (2012).

20. C. M. Hedgepeth, L. J. Conrad, J. Zhang, H. C. Huang, V. M. Lee, P. S. Klein, Activation of the Wnt signaling pathway: a molecular mechanism for lithium action. Developmental biology 185, 82-91 (1997).

21. K. A. Kim, M. Wagle, K. Tran, X. Zhan, M. A. Dixon, S. Liu, D. Gros, W. Korver, S. Yonkovich, N. Tomasevic, M. Binnerts, A. Abo, R-Spondin family members regulate the Wnt pathway by a common mechanism. Mol Biol Cell 19, 2588-2596 (2008).

22. S. Liu, L. C. Wu, J. Pang, R. Santhanam, S. Schwind, Y. Z. Wu, C. J. Hickey, J. Yu, H. Becker, K. Maharry, M. D. Radmacher, C. Li, S. P. Whitman, A. Mishra, N. Stauffer, A. M. Eiring, R. Briesewitz, R. A. Baiocchi, K. K. Chan, P. Paschka, M. A. Caligiuri, J. C. Byrd, C. M. Croce, C. D. Bloomfield, D. Perrotti, R. Garzon, G. Marcucci, Sp1/NFkappaB/HDAC/miR-29b regulatory network in KIT-driven myeloid leukemia. Cancer cell 17, 333-347 (2010).

23. M. Tan, J. Wu, Y. Cai, Suppression of Wnt signaling by the miR-29 family is mediated by demethylation of WIF-1 in non-small-cell lung cancer. Biochemical and biophysical research communications 438, 673-679 (2013).

24. K. Kapinas, C. Kessler, T. Ricks, G. Gronowicz, A. M. Delany, miR-29 modulates Wnt signaling in human osteoblasts through a positive feedback loop. The Journal of biological chemistry 285, 25221-25231 (2010).

25. J. K. Christman, 5-Azacytidine and 5-aza-2'-deoxycytidine as inhibitors of DNA methylation: mechanistic studies and their implications for cancer therapy. Oncogene 21, 5483-5495 (2002).

26. F. Belloc, F. Moreau-Gaudry, M. Uhalde, L. Cazalis, M. Jeanneteau, F. Lacombe, V. Praloran, F. X. Mahon, Imatinib and nilotinib induce apoptosis of chronic myeloid leukemia cells 
through a Bim-dependant pathway modulated by cytokines. Cancer Biol Ther 6, 912-919 (2007).

27. T. C. Chou, Drug combination studies and their synergy quantification using the Chou-Talalay method. Cancer Res 70, 440-446 (2010).

28. K. Silence, T. Dreier, M. Moshir, P. Ulrichts, S. M. Gabriels, M. Saunders, H. Wajant, P. Brouckaert, L. Huyghe, T. Van Hauwermeiren, A. Thibault, H. J. De Haard, ARGX-110, a highly potent antibody targeting CD70, eliminates tumors via both enhanced ADCC and immune checkpoint blockade. MAbs 6, 523-532 (2014).

29. B. Zhang, A. C. Strauss, S. Chu, M. Li, Y. Ho, K. D. Shiang, D. S. Snyder, C. S. Huettner, L. Shultz, T. Holyoake, R. Bhatia, Effective targeting of quiescent chronic myelogenous leukemia stem cells by histone deacetylase inhibitors in combination with imatinib mesylate. Cancer Cell 17, 427-442 (2010).

30. L. Li, L. Wang, Z. Wang, Y. Ho, T. McDonald, T. L. Holyoake, W. Chen, R. Bhatia, Activation of p53 by SIRT1 inhibition enhances elimination of CML leukemia stem cells in combination with imatinib. Cancer Cell 21, 266-281 (2012).

31. L. D. Shultz, B. L. Lyons, L. M. Burzenski, B. Gott, X. Chen, S. Chaleff, M. Kotb, S. D. Gillies, M. King, J. Mangada, D. L. Greiner, R. Handgretinger, Human lymphoid and myeloid cell development in NOD/LtSz-scid IL2R gamma null mice engrafted with mobilized human hemopoietic stem cells. Journal of immunology 174, 6477-6489 (2005).

32. A. Wilson, E. Laurenti, G. Oser, R. C. van der Wath, W. Blanco-Bose, M. Jaworski, S. Offner, C. F. Dunant, L. Eshkind, E. Bockamp, P. Lio, H. R. Macdonald, A. Trumpp, Hematopoietic stem cells reversibly switch from dormancy to self-renewal during homeostasis and repair. Cell 135, 1118-1129 (2008).

33. S. J. Neering, T. Bushnell, S. Sozer, J. Ashton, R. M. Rossi, P. Y. Wang, D. R. Bell, D. Heinrich, A. Bottaro, C. T. Jordan, Leukemia stem cells in a genetically defined murine model of blast-crisis CML. Blood 110, 2578-2585 (2007). 
34. A. Nakajima, H. Oshima, C. Nohara, S. Morimoto, S. Yoshino, T. Kobata, H. Yagita, K. Okumura, Involvement of CD70-CD27 interactions in the induction of experimental autoimmune encephalomyelitis. J Neuroimmunol 109, 188-196 (2000).

35. J. M. Kelly, P. K. Darcy, J. L. Markby, D. I. Godfrey, K. Takeda, H. Yagita, M. J. Smyth, Induction of tumor-specific T cell memory by NK cell-mediated tumor rejection. Nat Immunol 3, 83-90 (2002).

36. B. Zhang, Y. W. Ho, Q. Huang, T. Maeda, A. Lin, S. U. Lee, A. Hair, T. L. Holyoake, C. Huettner, R. Bhatia, Altered microenvironmental regulation of leukemic and normal stem cells in chronic myelogenous leukemia. Cancer Cell 21, 577-592 (2012).

37. M. Y. Konopleva, C. T. Jordan, Leukemia stem cells and microenvironment: biology and therapeutic targeting. J Clin Oncol 29, 591-599 (2011).

38. C. A. Huff, W. H. Matsui, B. D. Smith, R. J. Jones, Strategies to eliminate cancer stem cells: clinical implications. Eur J Cancer 42, 1293-1297 (2006).

39. M. A. Essers, A. Trumpp, Targeting leukemic stem cells by breaking their dormancy. Mol Oncol 4, 443-450 (2010).

40. M. Dean, T. Fojo, S. Bates, Tumour stem cells and drug resistance. Nat Rev Cancer 5, 275284 (2005).

41. M. B. Meads, L. A. Hazlehurst, W. S. Dalton, The bone marrow microenvironment as a tumor sanctuary and contributor to drug resistance. Clinical cancer research : an official journal of the American Association for Cancer Research 14, 2519-2526 (2008).

42. S. W. Lane, D. T. Scadden, D. G. Gilliland, The leukemic stem cell niche: current concepts and therapeutic opportunities. Blood 114, 1150-1157 (2009).

43. B. Zhang, M. Li, T. McDonald, T. L. Holyoake, R. T. Moon, D. Campana, L. Shultz, R. Bhatia, Microenvironmental protection of CML stem and progenitor cells from tyrosine kinase inhibitors through N-cadherin and Wnt-beta-catenin signaling. Blood 121, 1824-1838 (2013).

44. C. Schürch, C. Riether, M. A. Amrein, A. F. Ochsenbein, Cytotoxic T cells induce proliferation of chronic myeloid leukemia stem cells by secreting interferon-gamma. The Journal of experimental medicine 210, 605-621 (2013). 
45. J. Wischhusen, G. Jung, I. Radovanovic, C. Beier, J. P. Steinbach, A. Rimner, H. Huang, J. B. Schulz, H. Ohgaki, A. Aguzzi, H. G. Rammensee, M. Weller, Identification of CD70mediated apoptosis of immune effector cells as a novel immune escape pathway of human glioblastoma. Cancer Res 62, 2592-2599 (2002).

46. M. B. Bernstein, C. T. Garnett, H. Zhang, A. Velcich, M. M. Wattenberg, S. R. Gameiro, S. Kalnicki, J. W. Hodge, C. Guha, Radiation-induced modulation of costimulatory and coinhibitory T-cell signaling molecules on human prostate carcinoma cells promotes productive antitumor immune interactions. Cancer Biother Radiopharm 29, 153-161 (2014).

47. K. Kapinas, C. Kessler, T. Ricks, G. Gronowicz, A. M. Delany, miR-29 modulates Wnt signaling in human osteoblasts through a positive feedback loop. The Journal of biological chemistry 285, 25221-25231 (2010).

48. S. Dhut, B. Gibbons, T. Chaplin, B. D. Young, Establishment of a lymphoblastoid cell line, SD-1, expressing the p190 bcr-abl chimaeric protein. Leukemia 5, 49-55 (1991).

49. E. Klein, H. Ben-Bassat, H. Neumann, P. Ralph, J. Zeuthen, A. Polliack, F. Vanky, Properties of the K562 cell line, derived from a patient with chronic myeloid leukemia. Int J Cancer 18, 421-431 (1976).

50. B. Scappini, S. Gatto, F. Onida, C. Ricci, V. Divoky, W. G. Wierda, M. Andreeff, L. Dong, K. Hayes, S. Verstovsek, H. M. Kantarjian, M. Beran, Changes associated with the development of resistance to imatinib (STI571) in two leukemia cell lines expressing p210 Bcr/Abl protein. Cancer 100, 1459-1471 (2004).

51. R. Radpour, M. M. Haghighi, A. X. Fan, P. M. Torbati, S. Hahn, W. Holzgreve, X. Y. Zhong, High-throughput hacking of the methylation patterns in breast cancer by in vitro transcription and thymidine-specific cleavage mass array on MALDI-TOF silico-chip. Molecular cancer research : MCR 6, 1702-1709 (2008).

52. I. M. Carr, J. I. Robinson, R. Dimitriou, A. F. Markham, A. W. Morgan, D. T. Bonthron, Inferring relative proportions of DNA variants from sequencing electropherograms. Bioinformatics 25, 3244-3250 (2009).

53. H. Clevers, R. Nusse, Wnt/beta-catenin signaling and disease. Cell 149, 1192-1205 (2012). 


\section{Acknowledgments}

We thank Karen Silence for helpful discussions and Jürg Schwaller for providing retroviral vectors.

\section{Funding}

The Swiss National Science Foundation, the Swiss Cancer League, the Cancer League of the Canton of Bern, the Werner und Hedy Berger-Janser-Stiftung (A.F.O.), the Sassella Foundation (12/01), the Fondation BIOS pour la Recherche (C.R.), the Gertrud Hagmann-Stiftung für Malignomforschung, the SwissLife Jubiläumsstiftung, the Dr. Hans Altschüler-Stiftung, the Fondazione Dr. Carlo Gianella (C.M.S), the Mobiliar Jubiläumsstiftung, the Monika Kutzner Stiftung, the Stiftung Krebs-Hilfe and the Wolfermann-Nägeli Stiftung (C.R., C.M.S.).

\section{Author contributions}

C.R. and C.M.S. designed and performed experiments, analyzed and interpreted data and wrote and revised the manuscript. C.F., M.H., L.D., A.L.H. and R.R. performed experiments, analyzed and interpreted data and revised the manuscript. G.M.B. collected and contributed CML patient samples, interpreted data and revised the manuscript. A.F.O. designed experiments, analyzed and interpreted data and wrote and revised the manuscript.

\section{Competing interests}

The authors declare that they have no competing interests.

\section{Data and material availability}

Expression data are derived from a public repository for microarray data and are available under accession number E-MEXP-480 (http://www.ebi.ac.uk/arrayexpress). 


\section{Figure Legends}
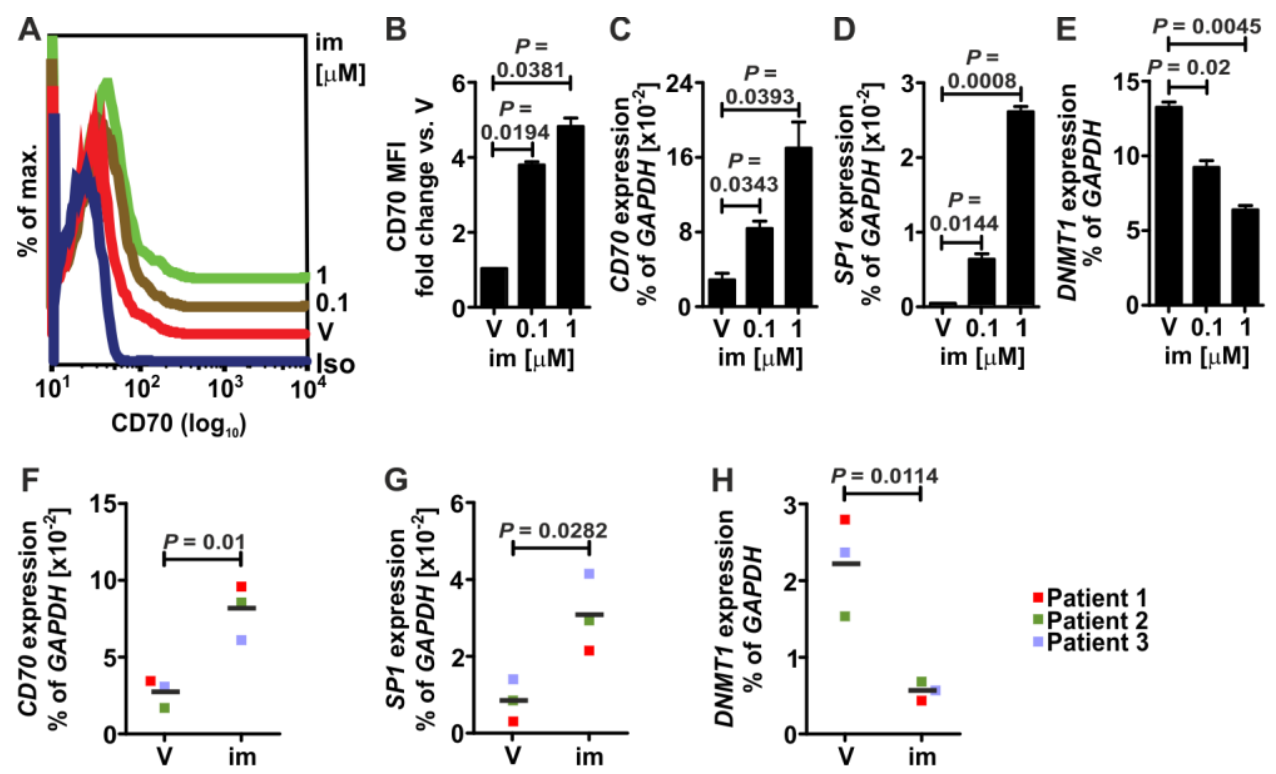

\section{-Patient 1}

- Patient

Patient 3
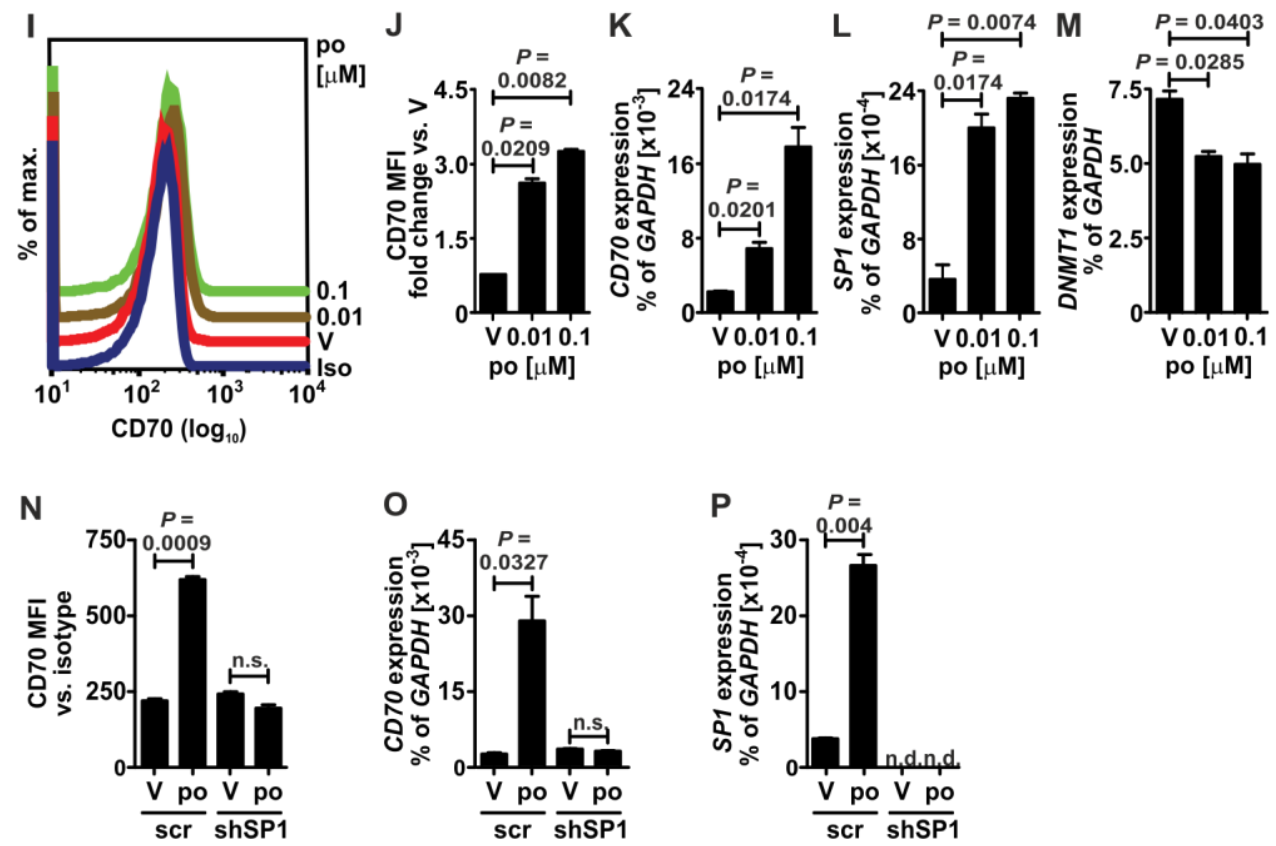

Fig. 1: TKI treatment induces CD70 expression on human CML cell lines and human CD34 ${ }^{+}$ CML stem/progenitor cells. (A-E) $1 \times 10^{5}$ KBM5 cells were cultured for $72 \mathrm{~h}$ in the presence of vehicle $\left(\mathrm{V}: \mathrm{H}_{2} \mathrm{O}\right)$ or imatinib (im) at the indicated concentrations. (A) Histograms and (B) mean fluorescence intensity (MFI) of CD70 protein expression (FACS). (C) CD70, (D) SP1, and (E) DNMT1 mRNA expression (qRT-PCR). (F-H) $1 \times 10^{4}$ FACS-sorted CD34 ${ }^{+}$stem/progenitor cells from the blood of newly diagnosed CML patients were cultured in liquid culture for 7 days in the presence of vehicle or imatinib $(1 \mu \mathrm{M})$. (F) CD70, (G) SP1 and (H) DNMT1 mRNA expression (qRT-PCR). (I- 
M) $1 \times 10^{5}$ imatinib-resistant KBM5r cells were cultured for $72 \mathrm{~h}$ in the presence of vehicle or ponatinib (po) at the indicated concentrations. (I) Histograms and (J) MFI of CD70 protein expression (FACS). (K) CD70, (L) SP1, and (M) DNMT1 mRNA expression (qRT-PCR). (N-P) 1x105 KBM5r cells transfected with shSP1 (shSP1) or the respective control scrambled RNA lentiviral particles (scr) were cultured for $72 \mathrm{~h}$ in the presence of vehicle or ponatinib (po, $0.1 \mu \mathrm{M})$. (N) MFI of CD70 protein expression (FACS). (O) CD70 and (P) SP1 mRNA expression (qRT-PCR). (B-E, J-M) Pooled data from two experiments run in duplicates and (N-P) data from one experiment run in duplicates are shown, respectively. Data are displayed as mean \pm s.e.m. Statistics: (B, J), one-sample t-test (hypothetical value 1); (C-H, K-P), student's t-test. 
A
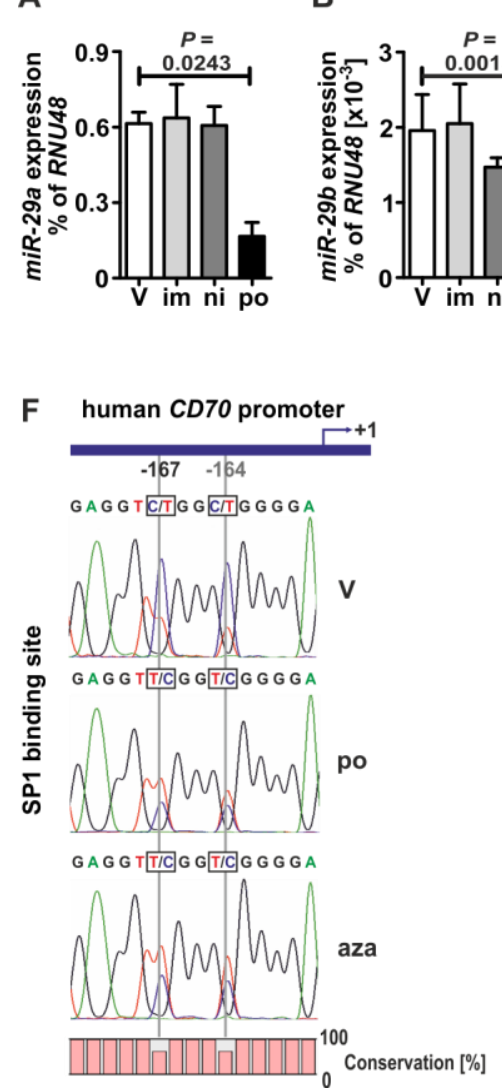

B

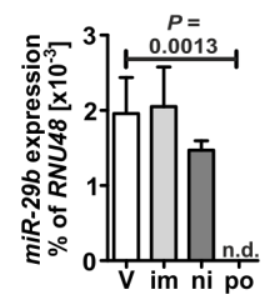

C

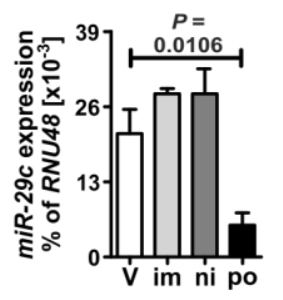

D

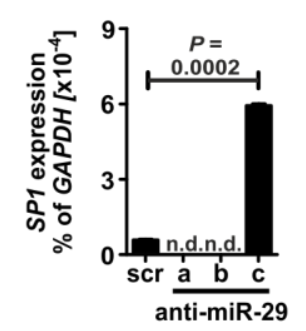

G

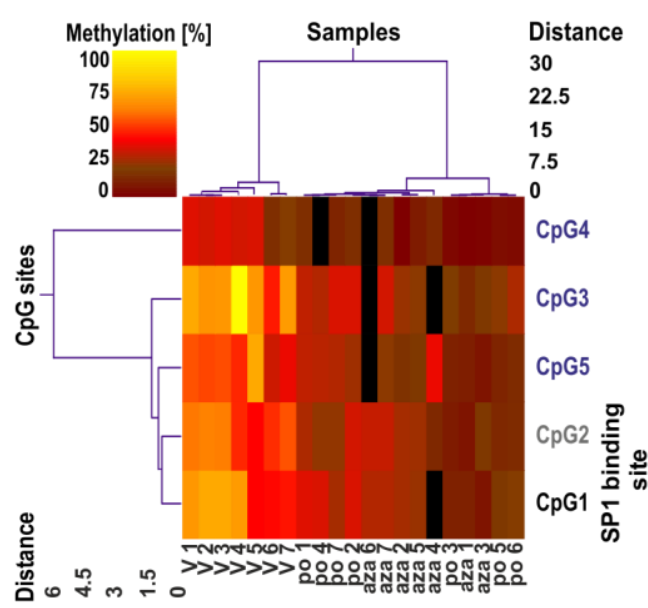

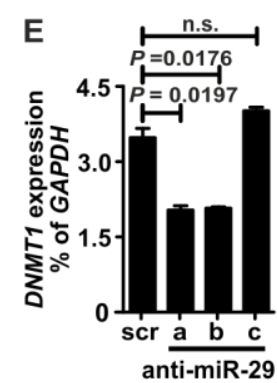

H

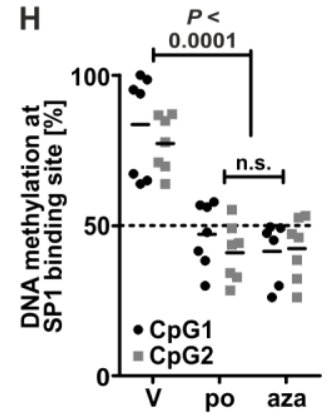

Fig. 2: TKI-mediated BCR-ABL1 inhibition down-regulates miR-29 levels, leading to SP1 expression and $C D 70$ promoter de-methylation. (A-C) $1 \times 10^{5} \mathrm{KBM} 5 \mathrm{r}$ cells were cultured in the presence of vehicle $\left(\mathrm{V}: \mathrm{H}_{2} \mathrm{O}\right.$ ), imatinib $(\mathrm{im}, 1 \mu \mathrm{M})$, nilotinib (ni, $1 \mu \mathrm{M}$ ) or ponatinib (po, $\left.0.1 \mu \mathrm{M}\right)$ for 72h and (A) $m i R-29 a$, (B) $m i R-29 b$ and (C) $m i R-29 c$ levels were determined (qRT-PCR). (D-E) $1 \times 10^{5}$ KBM5r cells were transfected with anti-miR-29a, anti-miR-29b or anti-miR-29c or scrambled control (scr) oligonucleotides for 48h and (D) SP1 and (E) DNMT1 mRNA expression was analyzed (qRTPCR). (F) Methylation status of the $C D 70$ promoter at the SP1 transcription factor binding site of KBM5r cells upon treatment with vehicle, ponatinib $(0.1 \mu \mathrm{M})$ or azacytidine $(1 \mu \mathrm{M})$ as determined by bisulfite sequencing. (G) Heat map of relative quantification of methylated cytosines at five critical CpG sites in the $C D 70$ promoter of KBM5r cells. (H) Semi-quantitative analysis of DNA methylation for $\mathrm{CpG} 1$ and $\mathrm{CpG} 2$ at the SP1 binding site. (A-C, D-E) Data from one experiment each, run in duplicates, are shown, respectively. (F-H) Pooled data from three independent experiments are shown. Data are displayed as mean \pm s.e.m. Statistics: student's t-test. 

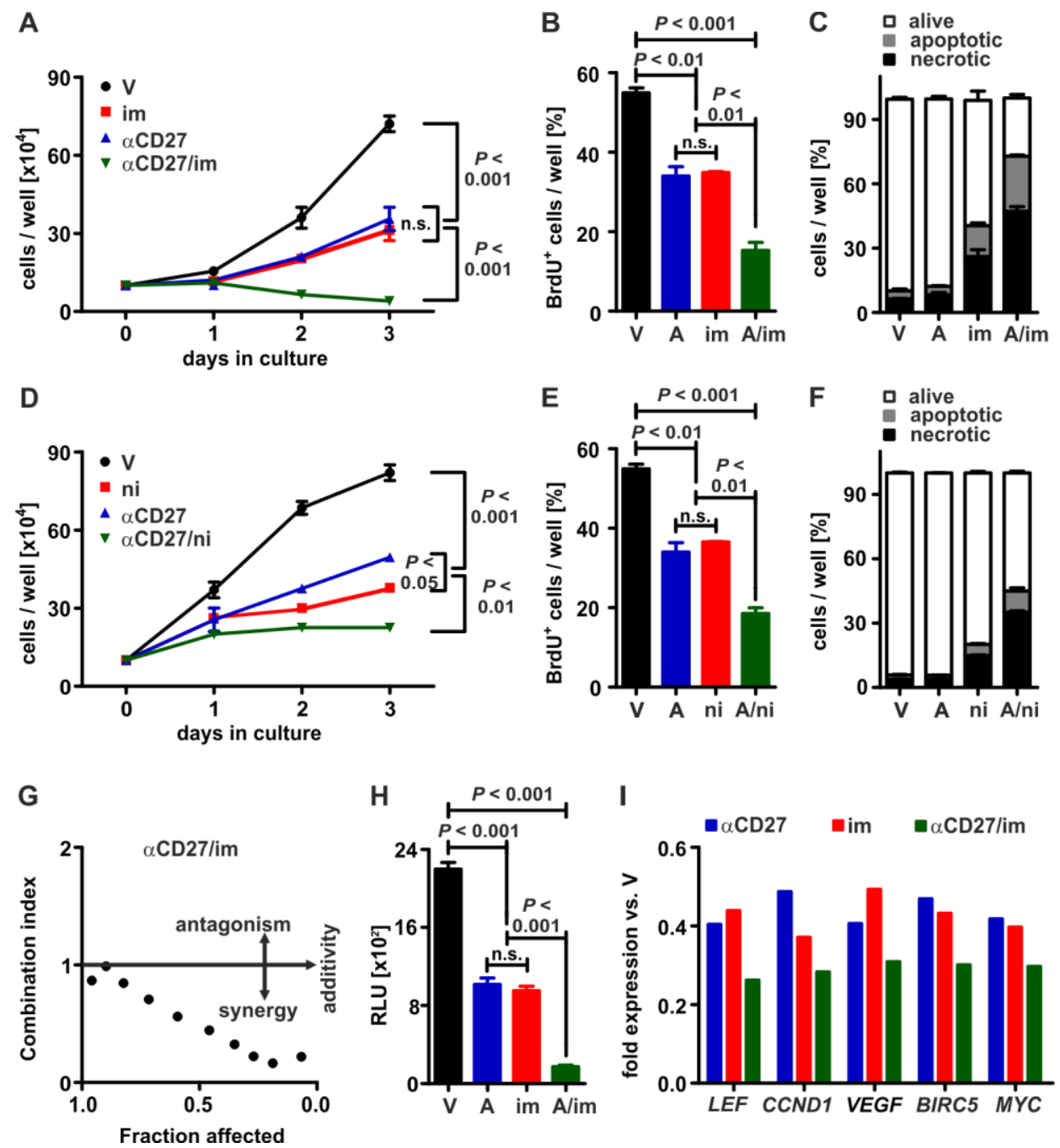

Fig. 3: BCR-ABL1 and CD70/CD27 co-inhibition synergistically eradicates SD-1 leukemia cells. (A-F) $1 \times 10^{5} \mathrm{SD}-1$ cells were cultured for $72 \mathrm{~h}$ in the presence of either vehicle ( $\left.\mathrm{V}: \mathrm{H}_{2} \mathrm{O}+\mathrm{IgG}\right), 10 \mu \mathrm{g} / \mathrm{ml}$ of $\alpha \mathrm{CD} 27$ blocking mAb (A: $\mathrm{H}_{2} \mathrm{O}+\alpha \mathrm{CD} 27$; clone $\left.15 \mathrm{H} 6\right), 1 \mu \mathrm{M}$ of imatinib (im: im+IgG) or $1 \mu \mathrm{M}$ of nilotinib (ni: ni+IgG) alone or both $\alpha \mathrm{CD} 27 / \mathrm{TKI}$ in combination. (A, D) Cell numbers, $(\mathbf{B}, \mathbf{E}) \mathrm{BrdU}$ incorporation and $(\mathbf{C}, \mathbf{F})$ cell viability were determined by trypan blue staining and FACS. Apoptotic and necrotic cells were defined as Annexin- $\mathrm{V}^{+}$and Annexin- $\mathrm{V}^{+} 7-\mathrm{AAD}^{+}$cells, respectively. (G) $1 \times 10^{5}$ SD-1 cells were treated with vehicle, $\alpha \mathrm{CD} 27$ or imatinib alone or in combination in a constant ratio. Cell numbers per well were counted after $72 \mathrm{~h}$ and the effect of drug treatment was calculated as a ratio of vehicle-treated cells. (H-I) $1 \times 10^{5}$ SD-1 cells were cultured in the presence of the compounds as described for (a-f) and activation of the Wnt pathway was assessed using (H) a TCF/LEF luciferase reporter assay after $24 \mathrm{~h}$ and (I) by analysis for the expression of selected Wnt target genes after $72 \mathrm{~h}$ 
(qRT-PCR). One representative experiment out of two run in duplicates is shown for each panel. RLU, relative luminescence units. Data are displayed as mean \pm s.e.m. Statistics: (A, D), two-way ANOVA; (B, E, H), one-way ANOVA. 
A

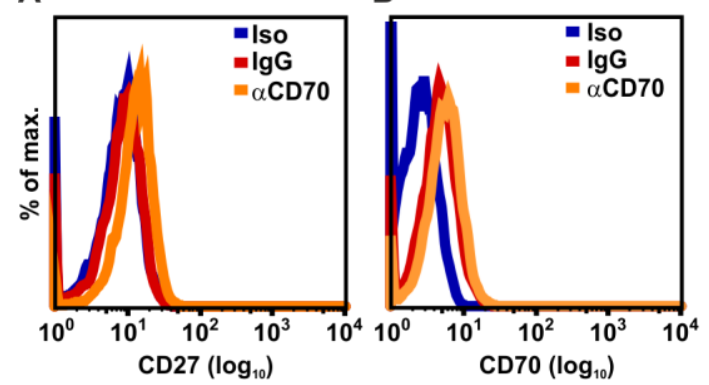

C

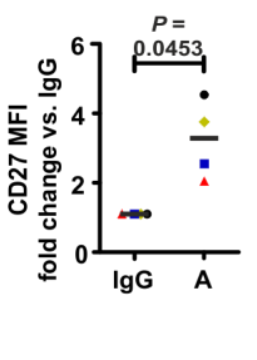

D

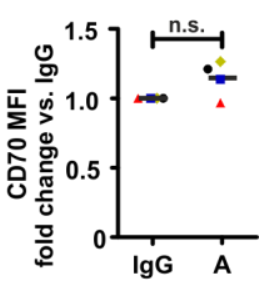

E
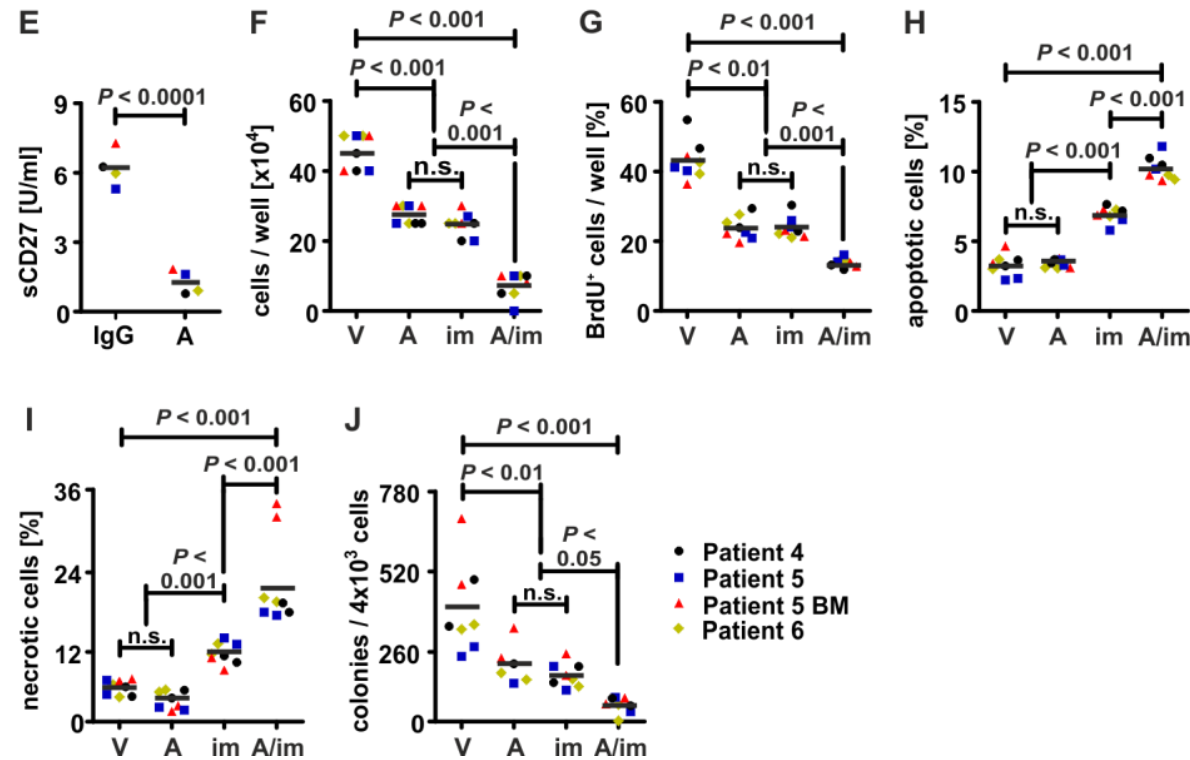

Fig. 4: $\alpha$ CD70 mAb/imatinib combination treatment eradicates human $\mathrm{CD34}^{+} \mathrm{CML}$ stem/progenitor cells in vitro. (A-E) $1 \times 10^{4}$ MACS-purified CD $34^{+}$stem/progenitor cells of newly diagnosed CML patients from blood $(n=3)$ or $B M(n=1)$ were cultured in duplicates in liquid culture in the presence of $10 \mu \mathrm{g} / \mathrm{ml}$ of $\operatorname{IgG}(\mathrm{IgG})$ or $\alpha \mathrm{CD} 70$ blocking $\mathrm{mAb}$ (A: clone 41D12-D). (A, B) Histograms and (C, D) mean fluorescence intensities (MFI) of CD27 and CD70 expression on CD34 CML stem/progenitor cells. (E) Soluble CD27 (sCD27) levels in supernatants after 7 days of culture. (F-J) $1 \times 10^{4}$ FACS-sorted CD34 ${ }^{+}$cells were cultured in duplicates in liquid culture in the presence of vehicle (V: $\left.\mathrm{H}_{2} \mathrm{O}+\mathrm{IgG}\right), 10 \mu \mathrm{g} / \mathrm{ml}$ of $\alpha \mathrm{CD} 70\left(\mathrm{~A}: \mathrm{H}_{2} \mathrm{O}+\alpha \mathrm{CD} 70\right.$ ), $1 \mu \mathrm{M}$ of imatinib (im: im+IgG) or both in combination (A/im: $\alpha$ CD70+imatinib). (F) Cell numbers, $(\mathbf{G})$ BrdU incorporation and $(\mathbf{H}, \mathbf{I})$ cell viability were determined by trypan blue staining and FACS after 7 days. Apoptotic and necrotic cells were defined as Annexin- $\mathrm{V}^{+}$and Annexin- $\mathrm{V}^{+} 7-\mathrm{AAD}^{+}$cells, respectively. (J) Duplicates of $4 \times 10^{3}$ FACS-sorted CD34 ${ }^{+}$CML stem/progenitor cells were cultured overnight in 96-well V-bottom plates in the presence of the compounds as described for $(\mathrm{B}-\mathrm{K})$ and were then transferred into 
methylcellulose containing the respective drugs. Colony formation was determined after 14 days by inverted light microscopy. Statistics: (C, D) one-sample t-test (hypothetical value 1); (E), student's ttest; (F-J) one-way ANOVA. 

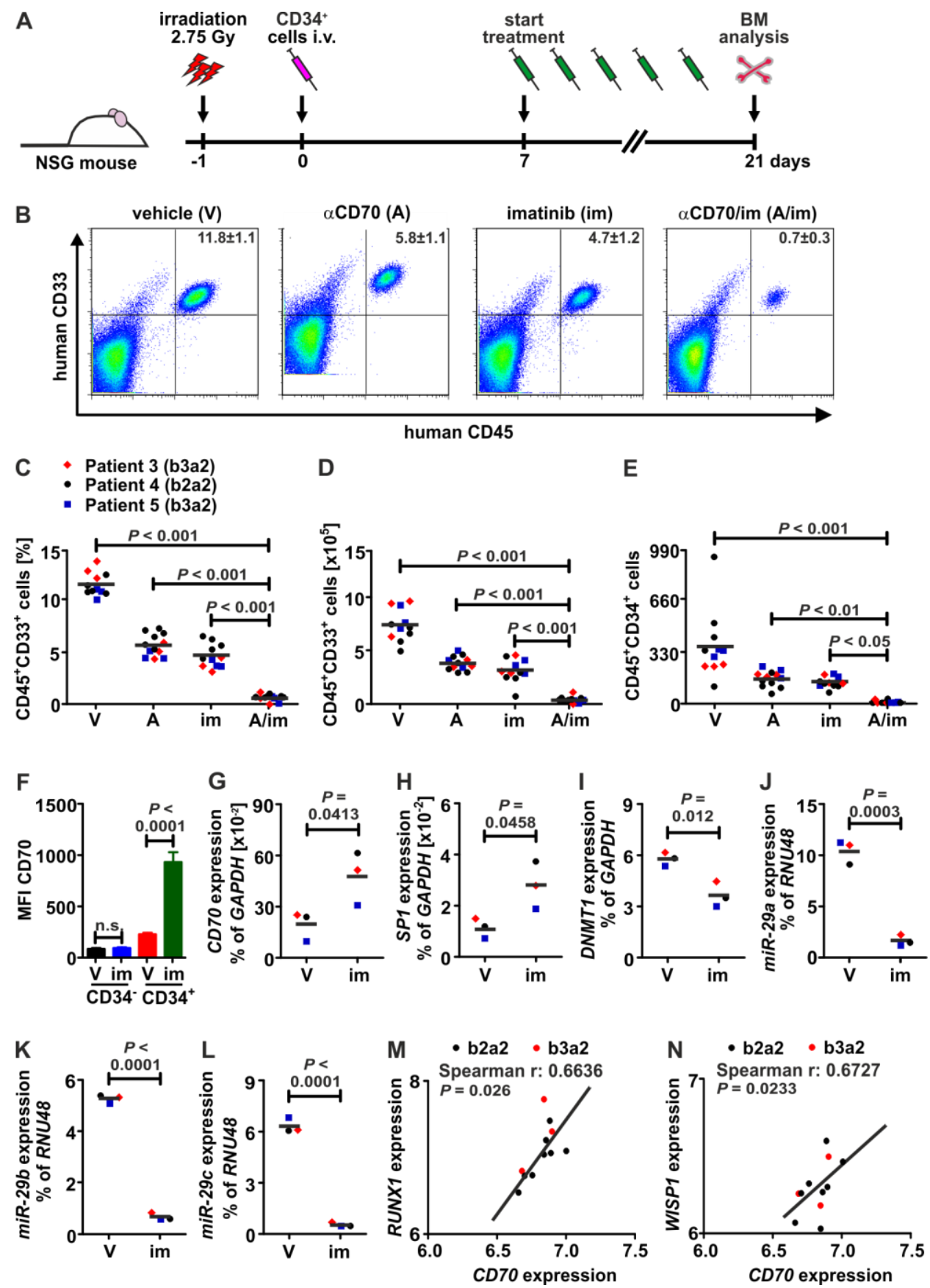

Fig. 5: $\alpha$ CD70 mAb/imatinib combination therapy eradicates human $\mathrm{CD34}^{+} \mathrm{CML}$ stem/progenitor cells in murine xenografts in vivo. (A-E) $2 \times 10^{6}$ MACS-purified CD $34^{+}$ stem/progenitor cells from the blood of three newly diagnosed CML patients were injected intravenously into irradiated (2.75Gy) NSG mice. Starting one week after transplantation, imatinib (im, $50 \mathrm{mg} / \mathrm{kg}$ ) was administered once daily by oral gavage. $10 \mathrm{mg} / \mathrm{kg}$ of $\alpha \mathrm{CD} 70$ (A) was administered intraperitoneally every $3^{\text {rd }}$ day. Sterile $\mathrm{H}_{2} \mathrm{O}$ and a control mAb specific for the F protein of respiratory syncytial virus (Pavilizumab, Synagis ${ }^{\circledR}$ ) were used as mock-treatment (V). (B) After 2 weeks of 
treatment, mice were euthanized and BM was analyzed for human cells by FACS. (C) Frequencies and (D) absolute numbers of human $\mathrm{CD} 45^{+} \mathrm{CD} 33^{+} \mathrm{CML}$ myeloid cells and (E) absolute numbers of human $\mathrm{CD} 45^{+} \mathrm{CD} 34^{+} \mathrm{CML}$ stem/progenitor cells in the BM. (F) MFI of CD70 expression on $\mathrm{CD} 45^{+} \mathrm{CD} 34^{-} \mathrm{CML}$ cells and $\mathrm{CD} 45^{+} \mathrm{CD} 34^{+} \mathrm{CML}$ stem/progenitor cells in xenografted NSG mice $(\mathrm{n}=3$ per xenograft and per treatment). (G) CD70, (H) SP1, (I) DNMT1 mRNA and (J-L) miR-29 expression (qRT-PCR) in CD34 ${ }^{+}$cells. (M, N) Correlation of $C D 70$ expression with the expression of selected Wnt target genes (M) RUNX1 and (N) WISP1 in CD34 ${ }^{+}$stem/progenitor cells from newly diagnosed chronic phase CML patients. Expression data are derived from a public repository for microarray data and are available under accession number E-MEXP-480 (http://www.ebi.ac.uk/arrayexpress). Data are displayed as mean \pm s.e.m. Statistics: (C-E) one-way ANOVA; (F-L) student's t-test; (M, N) Pearson's correlation. 

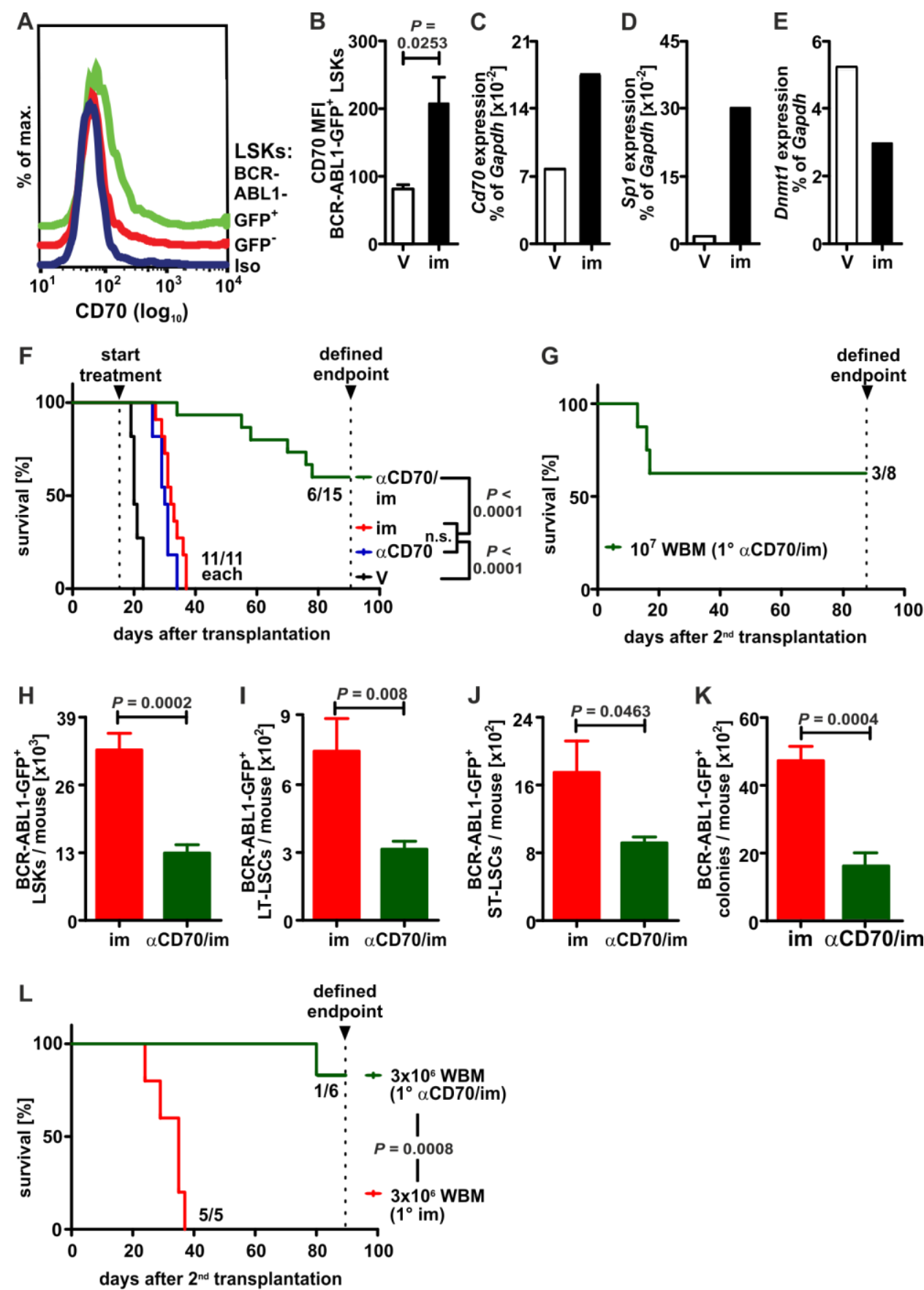

Fig. 6: $\alpha$ CD70 mAb/imatinib combination therapy eradicates LSCs and promotes long-term survival of CML mice. (A-E) BL/6 CML mice were treated with vehicle $\left(\mathrm{V}: \mathrm{H}_{2} \mathrm{O}, \mathrm{n}=5\right)$ or $50 \mathrm{mg} / \mathrm{kg}$ of imatinib (im, $\mathrm{n}=7$ ) once daily by oral gavage starting 15 days after transplantation. 10 days later, CD70 protein expression was analyzed by FACS in BCR-ABL1-GFP ${ }^{+}$LSKs and endogenous GFP $^{-}$ LSKs. (A) Representative histograms, (B) mean fluorescence intensity (MFI). (C) $C d 70$, (D) $S p 1$ and (E) Dnmt1 mRNA expression in FACS-sorted, pooled BCR-ABL1-GFP ${ }^{+}$LSKs (qRT-PCR). (F) 
Kaplan-Meier survival curves of primary BL/6 CML mice. Starting 15 days after transplantation, imatinib $(50 \mathrm{mg} / \mathrm{kg})$ was administered once daily by oral gavage. $300 \mu \mathrm{g}$ of $\alpha \mathrm{CD} 70$ blocking mAb (clone FR70) were administered intraperitoneally every $3^{\text {rd }}$ day. Sterile $\mathrm{H}_{2} \mathrm{O}$ and $\mathrm{IgG}$ from rat serum were used as controls. Pooled data from 2 independent experiments with $n=11-15$ mice per group are shown. (G) Survival of lethally irradiated $\left(2 \times 6.5\right.$ Gy) secondary recipients $(n=8)$ that received $1 \times 10^{7}$ whole BM (WBM) cells from $\alpha \mathrm{CD} 70 / \mathrm{im}$ treated primary CML mice $(\mathrm{n}=8)$ that were alive 90 days after primary transplantation. Data from one primary transplantation experiment with $n=8$ surviving animals are shown. (H-L) Primary BL/6 CML mice were treated with either imatinib alone $(\mathrm{n}=5)$ or with the combination therapy ( $\mathrm{n}=6)$ as described in (f) starting 15 days after transplantation. 10 days later, numbers of $(\mathbf{H})$ BCR-ABL1-GFP ${ }^{+}$LSKs, (I) BCR-ABL1-GFP ${ }^{+}$LT-LSCs (LSK CD135 CD48 $\mathrm{CD} 150^{+}$) and (J) BCR-ABL1-GFP ${ }^{+}$ST-LSCs $\left(\right.$LSK CD135 CD48 CD150 ${ }^{-}$) were determined in the BM (FACS). (K) Equal numbers of total $\operatorname{lin}^{-}$cells were plated in methylcellulose and BCR-ABL1$\mathrm{GFP}^{+}$colonies were enumerated 7 days later by inverted fluorescence microscopy. (L) $3 \times 10^{6} \mathrm{WBM}$ cells were transplanted into sublethally irradiated (4.5 Gy) recipient mice and survival was monitored. (F, G, L) Numbers of mice that succumbed to CML of total transplanted mice are indicated. Data are displayed as mean \pm s.e.m. Statistics: (B, H-K), student's t-test; (F,L), log-rank test. 

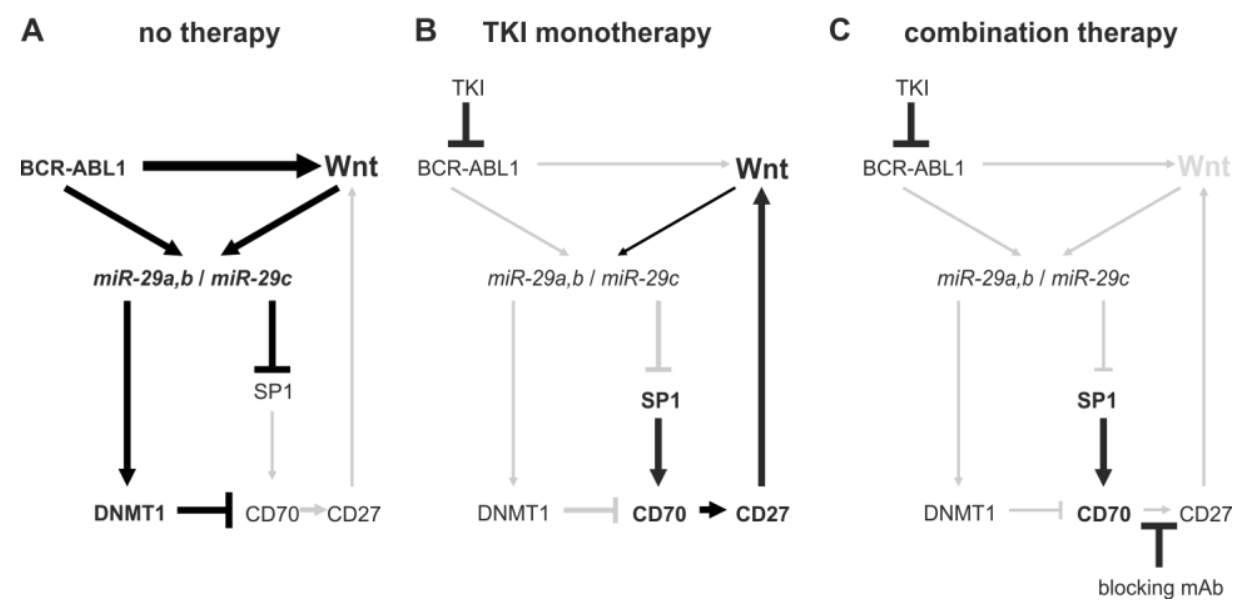

Fig. 7: Hypothesis of how combination therapy affects the Wnt pathway. The Wnt pathway is crucial for LSC survival and maintenance $(8,9)$. During homeostasis, the absence of Wnt ligand/Frizzled receptor signaling leads to $\beta$-catenin degradation via the proteasome (53). (A) In CML, the Wnt pathway is constantly active even in the absence of Wnt ligands because of BCR-ABL1mediated $\beta$-catenin stabilization/activation (7). (B) TKI treatment reduces BCR-ABL1-mediated Wnt pathway activation but simultaneously represses $m i R-29 s$. Down-regulation of $m i R-29 c$ results in SP1 up-regulation, whereas $m i R-29 a, b$ down-regulation is associated with a decrease in DNMT1 expression leading to $C D 70$ promoter DNA de-methylation. Together, these effects increase the expression of CD70, resulting in CD27-signaling and compensatory Wnt pathway activation. (C) Blocking of CD70/CD27-signaling by mAb in combination with TKI treatment synergistically inhibits the Wnt pathway and leads to LSC eradication. Solid lines, direct effects; dashed lines, indirect effects. 